\title{
Membranolytic Activity of Bile Salts: Influence of Biological Membrane Properties and Composition
}

\section{Patrick Garidel, Annegret Hildebrand, Katja Knauf and Alfred Blume*}

Martin-Luther-University Halle-Wittenberg, Institute of Chemistry, Physical Chemistry, Muehlpforte 1, D-06108 Halle/Saale, Germany

* Author to whom correspondence should be addressed: blume@chemie.uni-halle.de

Received: 9 September 2007; in revised form: 15 October 2007 / Accepted: 15 October 2007 / Published: 23 October 2007

\begin{abstract}
The two main steps of the membranolytic activity of detergents: 1) the partitioning of detergent molecules in the membrane and 2) the solubilisation of the membrane are systematically investigated. The interactions of two bile salt molecules, sodium cholate $(\mathrm{NaC})$ and sodium deoxycholate $(\mathrm{NaDC})$ with biological phospholipid model membranes are considered. The membranolytic activity is analysed as a function of the hydrophobicity of the bile salt, ionic strength, temperature, membrane phase properties, membrane surface charge and composition of the acyl chains of the lipids. The results are derived from calorimetric measurements (ITC, isothermal titration calorimetry). A thermodynamic model is described, taking into consideration electrostatic interactions, which is used for the calculation of the partition coefficient as well as to derive the complete thermodynamic parameters describing the interaction of detergents with biological membranes (change in enthalpy, change in free energy, change in entropy etc). The solubilisation properties are described in a so-called vesicle-to-micelle phase transition diagram. The obtained results are supplemented and confirmed by data obtained from other biophysical techniques (DSC differential scanning calorimetry, DLS dynamic light scattering, SANS small angle neutron scattering).
\end{abstract}

Keywords: Bile salt, liposome, phospholipid, vesicle, membranolytic, membrane, ITC, partitioning, solubilisation, thermodynamic. 


\section{Introduction}

Bile is a secretory and excretory fluid, which is secreted by the gall bladder into the intestine. Adult humans produce each day about $0.4-0.8 \mathrm{~L}$ of bile, which is a complex fluid containing water, inorganic compounds and a number of organic substances. Within the last fraction, lipids and bilirubin as well as different cholesterol and derivatives thereof were isolated. The earliest reliable data with regard to the composition of bile were presented years ago by Berzelius [1], Freiherrn von GorupBesanez [2] and Menzies [3]. The first source for the isolation of bile salts was bile extract [1-3]. In vertebrates, the two fundamental physiological functions of bile lie in the digestive nature of the bile fluid as well as being an excretory fluid [4]. The presence in the bile fluid of bile salts, which are effective digestive detergents, promotes the digestion and absorption of lipids and fats or fat-soluble vitamins in the small intestine. Many waste products, including bile salts (which are not only digestive detergents but also end products of cholesterol metabolism), bilirubin (the end product of heme metabolism), cholesterol (derived from the synthesis and exceeding body needs) and heavy metals such as iron and copper (also derived from absorption exceeding body needs), are removed from the body by secretion into bile and eliminated via faeces [5]. For drug elimination, the biliary secretion pathway presents an excretory route for lipophilic steroids and drug metabolites [6]. Although every day large quantities of bile salts are secreted into the intestine, only moderate amounts are lost from the human body, because approximately $95 \%$ of the bile salts delivered to the duodenum are reabsorbed into blood within the ileum. Based on this so-called enterohepatic circulation mechanism each bile salt molecule is "reused" about 20 times [7].

The concentration of phospholipids in the bile is quite high. Its fraction consists mainly of phosphatidylcholine (PC), and in the presence of bile salts, mixed systems i.e. mixed vesicles, mixed micelles, depending on the lipid to detergent ratio, are formed [8, 9]. It is described that the microdomains contained in the mixed micelles were able to solubilise cholesterol [10-14]. An important aspect in the formation of mixed micelles lies in the fact that the mixed micelle association lowers the monomeric activity of bile salts and thus prevents the solubilisation and thus destruction and membranolytic effect of the apical membrane of the epithelial cells $[15,16]$.

Table 1. The concentration of bile salts in different body compartments of humans [5, 8].

\begin{tabular}{|c|c|}
\hline Compartment & Concentration \\
\hline Gall bladder & $10-50 \mathrm{mmol} / \mathrm{L}$ \\
\hline Gut & $\sim 4-20 \mathrm{mmol} / \mathrm{L}$ \\
\hline Liver Canaliculi & $\sim 5 \mathrm{mmol} / \mathrm{L}$ \\
\hline Portal vein blood & $0.1 \mathrm{mmol} / \mathrm{L}$ \\
\hline Peripheral blood & $5-20 \mu \mathrm{mol} / \mathrm{L}$ \\
\hline
\end{tabular}


Species with a gall bladder, like humans, are able to further modify bile salts to e.g. taurocholic, chenodeoxycholic, glycocholic, taurochenodeoxycholic acids, or the bile salts can be metabolised by bacteria to lithocholic and ursodeoxycholic acids (for more details see [17, 18]). A further function of the gall bladder is the storage and concentration of bile (up to five-fold) during the fasting state. The physiology, biosynthesis and bile acid metabolism, however, is quite complex and has been reviewed recently $[4,5,7]$. The concentrations of bile salts in various body compartments are summarised in Table 1.

The chemical structure of bile salts (Figures 1A and 1B) is quite different, compared to the classical head-tail-detergents, where the hydrophilic head group and hydrophobic, flexible, hydrocarbon chains of the molecule are clearly separated (e.g. octyl glucoside (OG) or sodium dodecyl sulphate (SDS)) [19-21]. Bile salts have a rigid framework due to the steroid nucleus. Bile salt molecules bear a hydrophobic surface, which is the convex side of the rigid steroid ring system, and a polar surface, composed of the hydroxyl groups, forming the concave side of the molecule (Figure 1C). Because of the amphiphilic nature of bile salts they self-organise when they are transferred in an aqueous phase. The self-association is driven by the hydrophobic effect [22-24]. The combination of the rigidity of the molecule nucleus and the unusual chemical structure induce an aggregation behaviour, which is quite different to head-tail-detergents with aliphatic chains [23]. The dispersion of classical head-tail-detergents like OG or SDS in an aqueous phase induces spontaneously the aggregation of the monomer molecules into micelles. This happens above a specific detergent concentration denoted as the critical micelle concentration $(\mathrm{cmc})$ [24]. For head-tail-detergents large aggregates are often formed.

Under physiological conditions $\left(\approx 25^{\circ} \mathrm{C}, 300 \mathrm{mOsmol}, \mathrm{pH} 7\right)$ the aggregation number of such micelles can range, e.g. for SDS, between 50 and 80 SDS monomers per micelle [23, 25-27]. The size and shape of micelles and aggregation number is dependent on the environmental conditions like ionic strength, $p H$, temperature etc. Bile salts, however, due to the more or less "planar" hydrophobic and planar hydrophilic structure of the molecules (see Figure 1C), form much smaller micelles than the classical head-tail-detergents [20, 23, 28]. For sodium cholate ( $\mathrm{NaC})$ and sodium deoxycholate (NaDC) the aggregation number at room temperature is between $4-6$ molecules for $\mathrm{NaC}$ and higher for NaDC, with $7-12$ molecules (these micelles are denoted as primary micelles) [29, 30]. This property is not surprising, because the peculiar molecular structure of bile salts (Figure 1) does not really allow the formation of larger aggregate structures in order to isolate the hydrophobic part of the molecule from the aqueous phase. Compared to the classical head-tail-detergent, where a clear and sharp-defined $\mathrm{cmc}$ is detected, a well-defined $\mathrm{cmc}$ for bile salts does not really exist. This involves the formation of micelles as a continuous self-association process with increasing the total detergent concentration,. At very high bile salt concentrations so-called secondary micelles are formed (see below).

Various models of bile salt aggregate structures have been discussed over the last 50 years. Three models have been proposed: primary micelles, which are formed at low detergent concentration, having a disk shaped structure with one or two bile salt layers (model I) [31-33], and at higher detergent concentration, secondary micelles, where the aggregates are stabilised via hydrogen bondings between different primary micelles. Kawamura et al. [34] have proposed another model, where the aggregates form a disk shaped structure with a single bile salt layer (model II). In contrast, 
other results [35, 36] suggest a helical structure (model III) with counter ions and water on the axis of a helix. Recently the results presented by Warren et al. [37], analysing the spontaneous bile salt aggregation based on molecular dynamic simulations, have discounted the "helix-model". The results of their study revealed that the adoption of a disk shaped structure for bile salts is more likely.

Figure 1. Chemical structure of the two bile salts: (A) sodium cholate $(\mathrm{NaC})$ and $(\mathbf{B})$ sodium deoxycholate (NaDC). Under physiological conditions (300 mOsmol, pH 7) bile salts are negatively charged. (C) Structural formula of sodium cholate showing the hydrophobic surface (indicated in red) and the hydrophilic parts (indicated in blue) of the molecule.
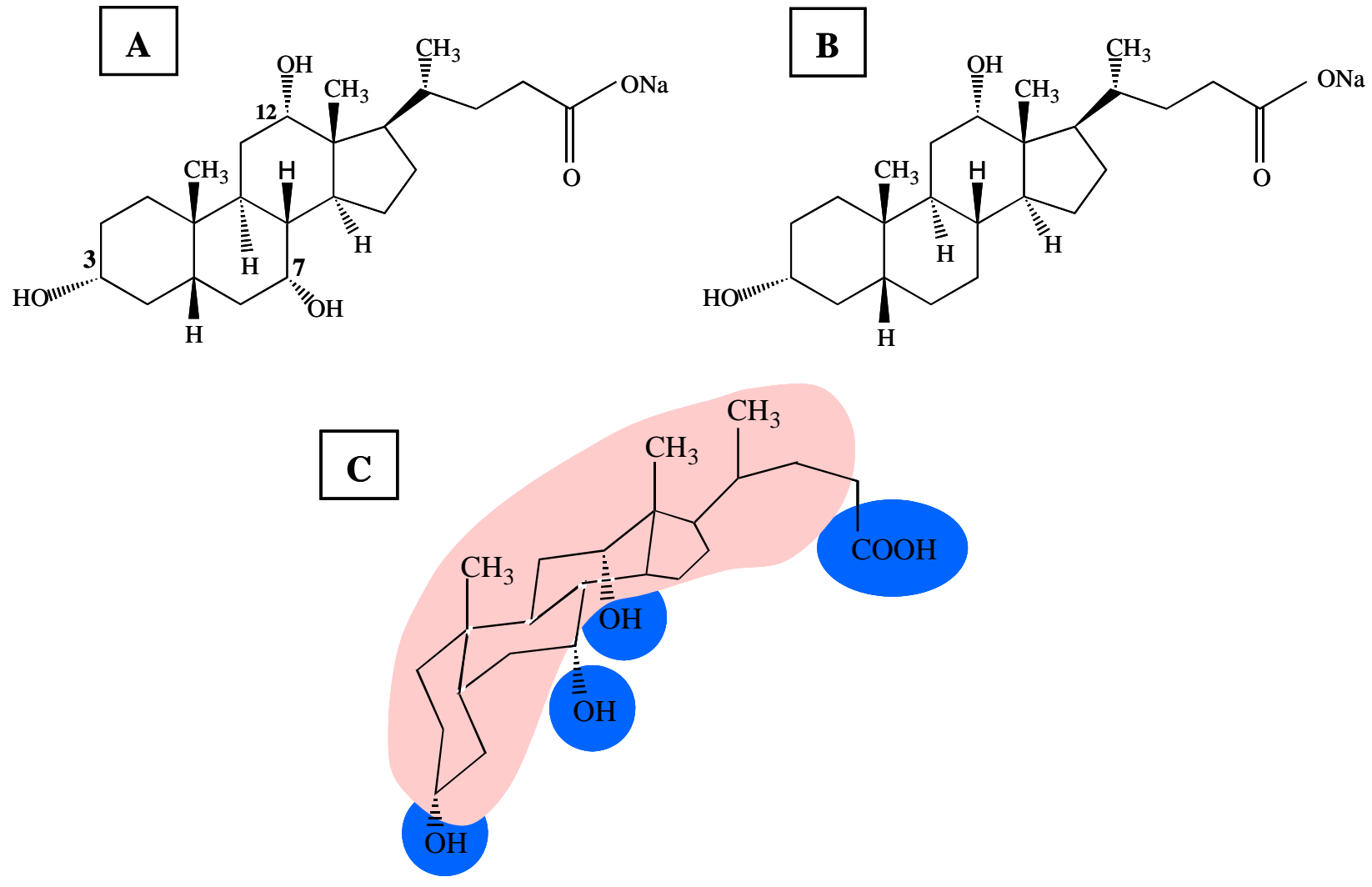

Various applications with bile salts have been reported [38-43]. Taminen and Kolekmainen [44] have recently reviewed the potential of bile acids as building blocks for the formation of supramolecular structures, which have been shown to possess molecular recognition properties. As an example bile acid-porphyrin conjugates are investigated with respect to their saccharide binding capacities [45-47]. Other applications are described, especially in the field of protein biochemistry in order to use bile salts for the isolation of membrane bound proteins or other structures [23, 41, 48, 49].

In the field of pharmaceutical sciences, bile salt micelles and derived mixed systems are intensively investigated, because of their potential as drug carrier systems [39, 40,41, 43, 50]. One advantage using such carrier systems is the increased drug solubility in the presence of bile salt micelles or mixed micelles (often formed with lipids) [39, 40].

Various therapeutic drugs are commercialised as formulations containing bile salts, phospholipids and/or fatty acids. A commercial product with the trade name Valium ${ }^{\circledR} \mathrm{MM}[41$, 51] for i.v. 
application contains the tranquilizer diazepam, a 1,4-benzodiazepin derivative, "solubilised" in mixed micelles (MM). The formulation contains glycocholic acid and soy lecithin as well as benzyl alcohol (preservative), sodium bisulfite, sodium chloride $(\mathrm{HCl}$ and $\mathrm{NaOH})$ and water for injection.

The reason why some commercial bile acid formulations contain lipids lies in the fact that the membranolytic activities of the detergents in the mixed system is strongly reduced, and thus the used detergents become less haemolytic $[15,41]$. On the other hand, membranolysis of bacterial membranes is a key strategy for the development of antimicrobial components [52, 53]. The mechanism of membranolysis of e.g. amphiphilic peptide drugs is largely investigated in order to understand the concepts how to design the peptides and thus to generated highly potent antimicrobial drugs. However, it is also observed that the antimicrobial activity depends on the tested microorganisms and can cover the range from no antimicrobial activity up to very strong activity. One reason for this is the different lipid composition of the membrane of the microorganism [8, 11, 12, 15], which strongly influences the membranolytic activity of detergents or peptides.

Therefore, this paper deals with the investigation of the membranolytic properties of two bile salts: sodium cholate $(\mathrm{NaC})$ and sodium deoxycholate $(\mathrm{NaDC})$ (Figures $1 \mathrm{~A}$ and $1 \mathrm{~B})$. The two main steps in membranolysis, the partitioning of the detergent in the membrane as well as the complete disruption and solubilisation of the membrane are investigated in more detail (see Figure 2).

Figure 2. Schematic phase diagram of lipid/detergent mixtures, a so-called total detergent concentration $\left(D_{\mathrm{t}}\right)$ versus lipid concentration $(L)$ phase diagram, representing the liposome to micelle transition. The blue and red lines indicate the phase boundaries $D_{\mathrm{t}}^{\text {sat }}$ and $D_{\mathrm{t}}^{\text {sol }}$ for saturation (sat) respectively solubilisation (sol) process. The detergent to lipid ratio is given by $R_{\mathrm{e}}^{\text {sat }}$ and $R_{\mathrm{e}}^{\text {sol }}$, and the hypothetical detergent concentration in the presence of lipid $D_{\mathrm{w}}^{\text {sat }}$ and $D_{\mathrm{w}}^{\text {sol }}$ for the saturation and solubilisation. $L_{\alpha}$ : liquid crystalline phase, $L_{1}$ micellar phase.

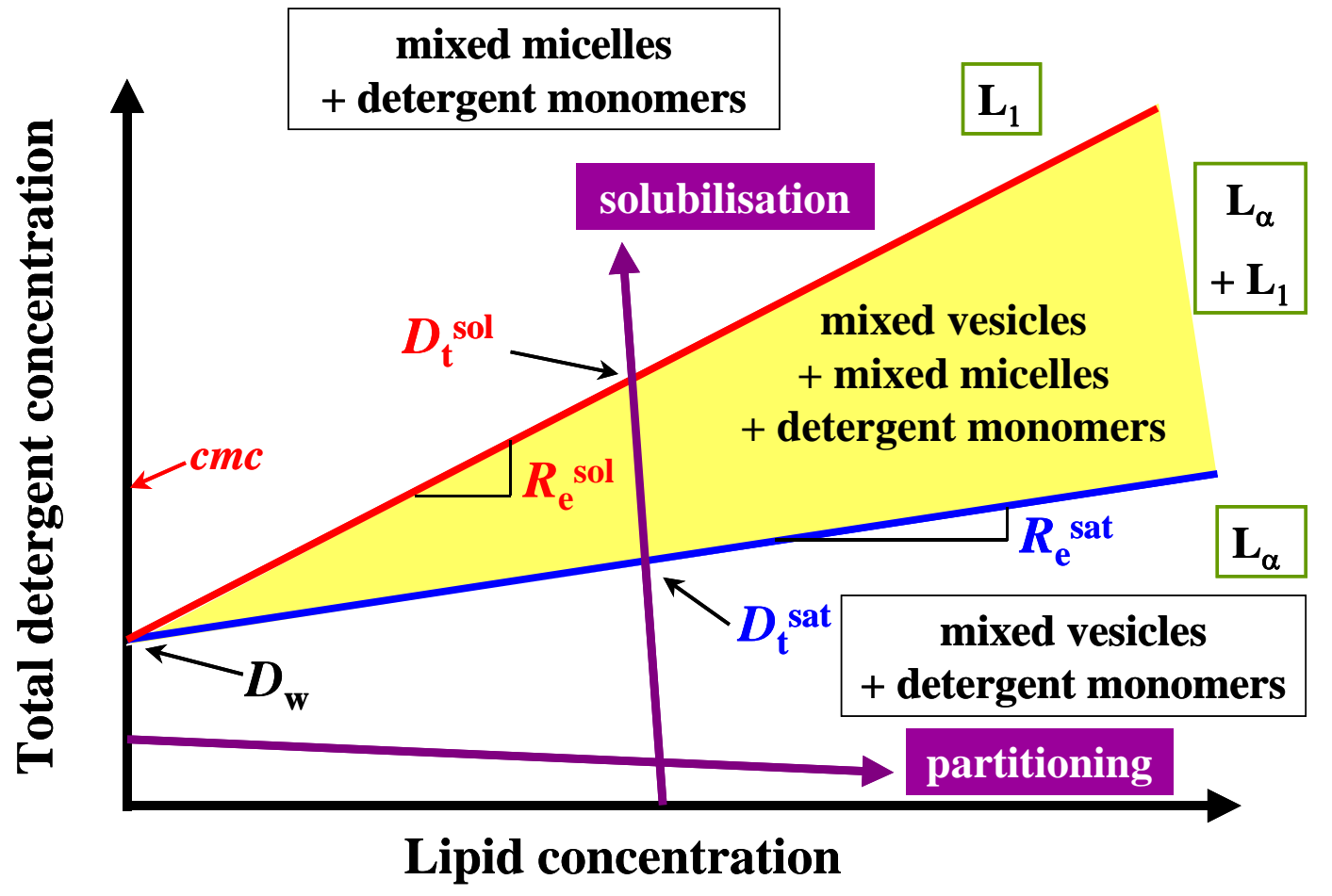


$\mathrm{NaC}$ is the tri-hydroxy, whereas $\mathrm{NaDC}$ is the di-hydroxy bile salt variant. Under physiological conditions bile salts are negatively charged and bear one negative element charge. Clearly defined phospholipid model membranes (liposomes) were used [54], in order to understand unambiguously the membranolytic detergent effect. Additionally, environmental conditions like temperature, ionic strength were considered.

The interaction of bile salts and their membranolytic activity was investigated as a function of:

- bile salt hydrophobicity

- ionic strength

- temperature

- chain length of phospholipids

- saturation degree of the acyl chains of the membrane

- surface charge density of the membrane

- membrane phase properties

Information was derived from isothermal titration calorimetry (ITC), dynamic light scattering (DLS), differential scanning calorimetry (DSC), and some structural data are supplemented by small angle neutron scattering (SANS).

\section{Theoretical considerations and calculations}

Investigation of detergent water to membrane partitioning by ITC

A typical ITC partition experiment is shown in Figure 3 [54-58]. The syringe is loaded with a highly concentrated phospholipid dispersions and injected into the detergent solution at a concentration lower than the $\mathrm{cmc}$ (Figure 3A). Figure 3B shows the titration partitioning experiment of $\mathrm{NaC}$ into soy bean phosphatidylcholine (SPC) vesicles in $0.1 \mathrm{M} \mathrm{NaCl}$ at $T=30^{\circ} \mathrm{C}$ and $T=60^{\circ} \mathrm{C}$.

During the partition experiment liposomes are titrated to the detergent monomer solution, and with increasing amount of added lipid, the amount of free detergent into the cell is consequently reduced, and thus less and less detergent is available for the incorporation into the liposomal membrane (lipid phase). As a consequence, consecutively smaller exothermic heat effects are registered (Figure 3B). The effects measured are dependent on the temperature, as can be seen by comparing Figures 3B' and 3B', which indicate that the detergent partitioning is temperature dependent. The final lipid injections are characterised by nearly constant reaction heats, corresponding to the dilution heat of the liposome dispersion. At the end of the partitioning titration experiment shown in Figure 3, the lipid concentration in the sample cell is approximately $3.5 \mathrm{mM}$. This corresponds to a final molar lipid to detergent ratio of about 1.0 .

The reaction heat $Q$ of each injection is obtained by integrating the area under each peak, and is plotted as a function of the total lipid concentration $L$ in the sample cell (Figures 3C' and 3C',). At 30 ${ }^{\circ} \mathrm{C}$ a continuous change in the reaction heat from $-400 \mu \mathrm{J}$ to $-100 \mu \mathrm{J}$ is observed, whereas at $60{ }^{\circ} \mathrm{C}$ a continuous change in the reaction heat from $-900 \mu \mathrm{J}$ to $-200 \mu \mathrm{J}$ is detected [59]. 
Figure 3. (A) Schematic representation of an ITC partition experiment. The syringe is loaded with a liposome dispersion and is titrated to a monomer detergent solution ( $c_{\text {cell }}($ detergent $\left.)<c r c\right)$. (B) Titration of a SPC (soy bean phosphatidylcholine) liposome dispersion (20 mM, 0.1 M NaCl, pH 7.4) into $\mathrm{NaC}(4 \mathrm{mM}, 0.1 \mathrm{M} \mathrm{NaCl}, p H 7.4)$ in steps of $5 \mu \mathrm{l}, 50$ injections. (B') calorimetric traces at $30{ }^{\circ} \mathrm{C}$ and (B') $60{ }^{\circ} \mathrm{C}$. The derived reaction heat $\Delta Q$ of each injection versus lipid concentration (SPC) in the cell is represented in (C') for $30^{\circ} \mathrm{C}$ and $\left(\mathrm{C}^{\prime \prime}\right) 60^{\circ} \mathrm{C}$.
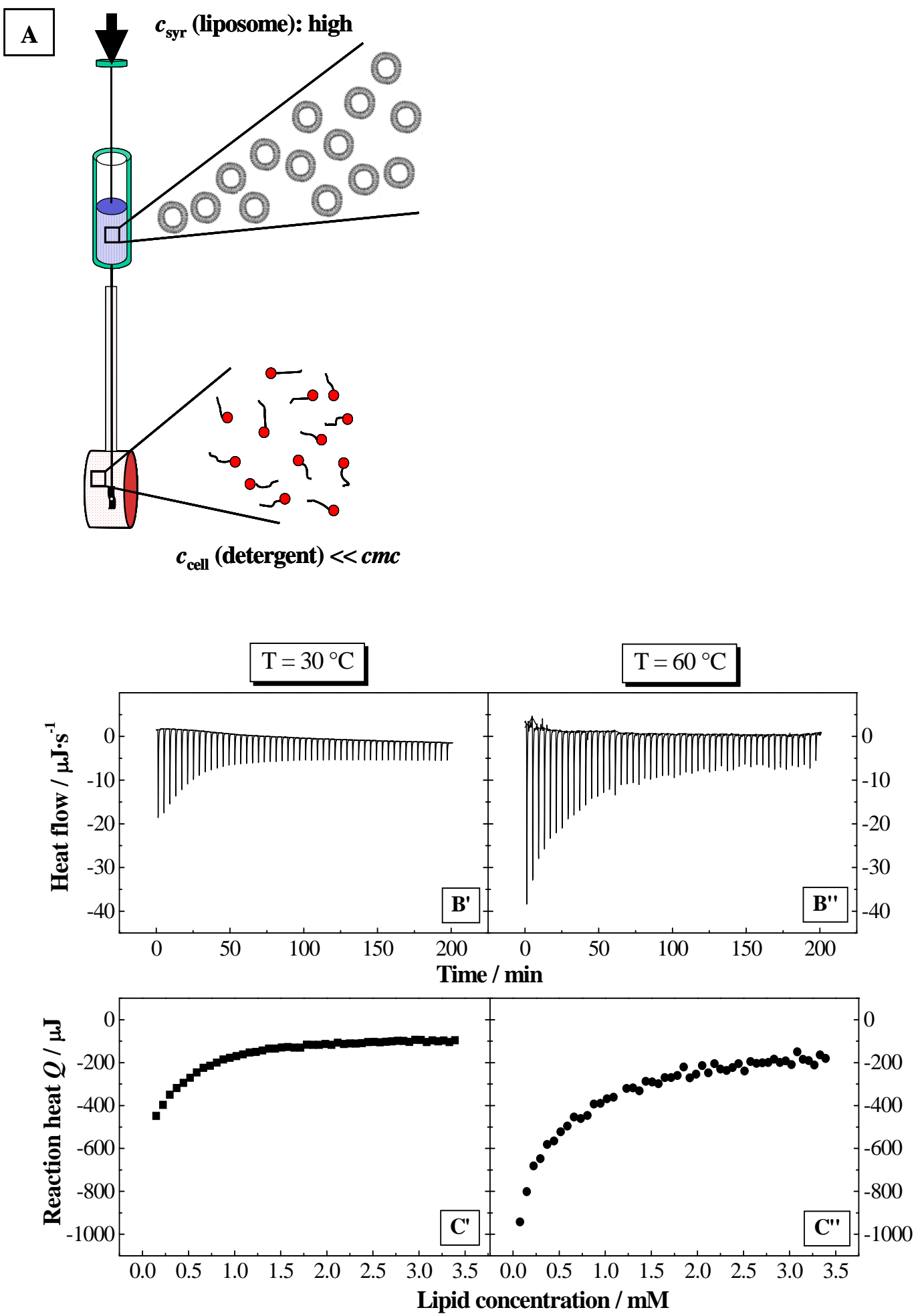
The model used for the calculation of the partition coefficient $P$ and the heat of transfer $\Delta H^{\mathrm{T}}$ of detergent molecules from water to lipid vesicles takes into account electrostatic effects. The partition coefficient $P$ is defined as the ratio of the mole fractions of bound detergent in the mixed membrane (composed of lipid and detergent) $x_{\mathrm{b}}$ and free detergent in the aqueous solution $x_{\mathrm{w}}$ :

$$
P=\frac{x_{\mathrm{b}}}{x_{\mathrm{w}}}
$$

At pH 7.4 PCs are zwitterionic, whereas bile salts are negatively charged. As a consequence of the incorporation of negatively charged bile salt molecules into PC membranes, an increase of the negative surface charge density of the liposomes is induced, which hampers further incorporation of additional detergent molecules. Accordingly, the electrostatic repulsion between negatively charged bile salt molecules and bile salt containing lipid liposomes has to be considered. Kuchinka and Seelig [60] have presented an approach enabling the incorporation of these electrostatic effects for the calculation of the partitioning coefficient. First the surface charge density $\sigma$ has to be calculated according to:

$$
\sigma=z \cdot e_{0} \cdot \frac{\frac{D_{\mathrm{b}}}{L \cdot A_{\mathrm{L}}}}{1+\frac{D_{\mathrm{b}} \cdot A_{\mathrm{D}}}{L \cdot A_{\mathrm{L}}}}
$$

For bile salts $z=-1$ (electric charge of the bile salt), $e_{0}$ is the elementary electric charge, $D_{\mathrm{b}}$ the concentration of bound detergent, $L$ the lipid concentration in the sample cell, $A_{\mathrm{L}}$ the average lipid molecular surface area (e.g. for POPC and DPPC molecule $A_{\mathrm{L}} \approx 65 \AA^{2}$ ) [61, 62] and $A_{\mathrm{D}}$ the average bile salt molecular surface area $\left(A_{D} \approx 40 \AA^{2}\right)[56,62]$.

The surface potential $\psi_{0}$, for 1:1 electrolytes, is calculated by means of the Grahame equation [23, 63, 64]:

$$
\psi_{0}=-k_{\mathrm{B}} \cdot \frac{T}{e_{0}} \cdot \operatorname{acosh}\left(\frac{\sigma^{2}}{4 \varepsilon_{0} \varepsilon_{\mathrm{r}} R T \cdot 1000 \cdot c_{\mathrm{el}}}+1\right)
$$

where $k_{\mathrm{B}}$ is the Boltzmann constant, $T$ the absolute temperature, $e_{0}$ the elementary electric charge, $\varepsilon_{0}$ the permittivity of free space, $\varepsilon_{\mathrm{r}}$ the dielectric constant of water, $R$ the gas constant, and $c_{\mathrm{el}}$ the electrolyte concentration.

$\psi_{0}$ is integrated in Equation 4 in order to calculate the partition coefficient $P$ :

$$
P=P_{0} \cdot \exp \left(-\frac{z \cdot e_{0} \cdot \psi_{0}}{k_{\mathrm{B}} \cdot T}\right) \cdot \exp \left(-\rho \frac{\left(1-x_{\mathrm{b}}\right)^{2}}{R \cdot T}\right)
$$

$P_{0}$ is the intrinsic detergent partition coefficient considering the presence of lipid vesicles and the nonideal mixing of detergents in a lipid membrane is expressed as the nonideality parameter $\rho$.

The concentration of bound detergent $D_{\mathrm{b}}$ is given as a function of the total detergent concentration in the sample cell $D_{\mathrm{t}}$ (total detergent concentration) taking the molar water concentration $W$ (55.5 mol.l $\mathrm{l}^{-1}$ ) into account:

$$
D_{\mathrm{b}}=\frac{1}{2}\left(D_{\mathrm{t}}-L\right)-\frac{W}{2 P}+\sqrt{\frac{1}{4}\left(D_{\mathrm{t}}+L\right)^{2}-\frac{1}{2}\left(D_{\mathrm{t}}-L\right) \cdot \frac{W}{P}+\frac{1}{4}\left(\frac{W}{P}\right)^{2}}
$$


With the approximation for the bulk concentration of the detergent $D_{\text {wbulk: }}$ :

$$
D_{\text {wbulk }}=D_{\mathrm{t}}-D_{\mathrm{b}}
$$

and applying the Gouy-Chapman theory, the detergent concentration at the membrane surface $D_{\text {w }}$ is calculated as [63]:

$$
D_{\mathrm{w}}=D_{\text {wbulk }} \cdot \exp \left(-\frac{z \cdot e_{0} \cdot \psi_{0}}{k_{\mathrm{B}} \cdot T}\right)
$$

The change of the bound detergent concentration $\Delta D_{\mathrm{b}}$ in the membrane as a function of the injected phospholipid dispersion is given by:

$$
\frac{\Delta D_{\mathrm{b}}}{\Delta L}=\frac{D_{\mathrm{b}(\mathrm{n}+1)}-D_{\mathrm{b}(\mathrm{n})}}{L_{(\mathrm{n}+1)}-L_{\mathrm{n}}}
$$

The concentration differences in $D_{b}$ and $L$ between the $(n+1)^{\text {th }}$ and the $n^{\text {th }}$ injection have to be implemented in equation 8.

The link of equation 8 to the experimentally observed reaction heat $\Delta Q$ is:

$$
\Delta Q=\left(\frac{\Delta D_{\mathrm{b}}}{\Delta L} \cdot \Delta H^{\mathrm{T}}+\Delta H_{\mathrm{dil}}\right) \cdot L_{\mathrm{t}, \mathrm{syr}} \cdot V_{\mathrm{inj}}
$$

where $L_{\mathrm{t}, \mathrm{syr}}$ is the total lipid concentration in the syringe and $V_{\mathrm{inj}}$ the injected volume. $\Delta Q$ is determined by the transfer enthalpy $\Delta H^{\mathrm{T}}$ of the inclusion of detergent monomers into the lipid membrane and the heat of dilution $\Delta H_{\text {dil }}$ of the phospholipid dispersion. $\Delta H_{\text {dil }}$ is obtained from a separate experiment by titrating the phospholipid dispersion into the solvent and subtracting the dilution term from the reaction heat change $\Delta Q$ or from the last injections.

For the calculation of the partition coefficients $P$ and the transfer $\Delta H^{\mathrm{T}}$ enthalpy a two-parameter non-linear least square fit is chosen. Two partition coefficients are calculated, $P_{0}$ and $P_{\mathrm{av}}$, with $P_{\mathrm{av}}$ being the average partition coefficient describing the partition in the "middle" of the partition experiment. Related to Figure $3 \mathrm{~B}, P_{\mathrm{av}}$ reflects the detergent partition between $20^{\text {th }}$ and $30^{\text {th }}$ injections.

The changes in Gibbs free energy $\Delta G^{\mathrm{T}}{ }$ (\# means ' 0 ' or 'av') are calculated according to:

$$
\Delta G_{\#}^{\mathrm{T}}=-R T \cdot \ln P_{\#}
$$

and the entropy term $T \Delta S^{\mathrm{T}}$ is obtained from the Gibbs-Helmholtz-equation:

$$
T \Delta S_{\#}^{\mathrm{T}}=\Delta H^{\mathrm{T}}-\Delta G^{\mathrm{T}}
$$

The thermodynamic parameters $\Delta G^{\mathrm{T}}$ and $T \Delta S^{\mathrm{T}}{ }_{\#}$ are calculated for the intrinsic partition coefficient $P_{0}$ and the average partition coefficient $P_{\mathrm{av}}[41,56,62,64,65]$.

Investigation of membrane solubilisation by ITC

The titration of highly concentrated detergent solution into a liposome dispersion induces strong changes in the liposome morphology [41, 66-70]. This is schematically represented in Figure 4. Various stages, denoted by I to VII, are shown. In the presence of very low amounts of detergent molecules, some are incorporated in the outer layer of the membrane (Figure 4II), and with further increases of the detergent concentration, the amount of membrane bound detergent increases. At this 
stage, there is a distribution of monomer detergent molecules (at concentrations below the $\mathrm{cmc}$ ) between the lipid membrane phase and the bulk aqueous water phase and mixed vesicles are formed. Furthermore, a flip-flop process takes place [71], transporting the detergent to the inner layer of the membrane and vice versa until equilibrium is reached (Figure 4III). Due to the higher amount of total detergent and thus higher amount of incorporated detergent molecules in the liposome, the size of the liposome increases. This can be measured by DLS (see below). However, with increasing the total detergent concentration $D_{\mathrm{t}}$, a critical detergent concentration $D_{\mathrm{t}}^{\text {sat }}$ is reached where the mixed bilayers are saturated with detergent molecules (Figure 4IV) and the liposomes cannot incorporate more detergent molecules. As a consequence, the liposomes start to break up, change their morphology and fragment into mixed micelles (Figure 4V). Increasing the amount of detergent shifts the transformation form mixed vesicles to mixed micelles (Figure 4VI). Mixed aggregates of both species, liposomes and micelles, occur in the coexistence region (Figure 4V). With further increases of the detergent concentration a second critical detergent concentration $D_{\mathrm{t}}^{\text {sol }}$ is reached (Figure 4VI), beyond which all liposomes have disappeared and the solubilisation is completed. The presence of extremely high detergent concentrations change the morphology of mixed micelles as has been described in the literature. Lasch [21, 41] differentiates between lipid-rich mixed micelles (Figure 4VI) and detergentrich mixed micelles (Figure 4VII) with smaller particle sizes, which are observed at high detergent to lipid ratios. In all stages (I-VII) shown in Figure 4 the aggregates coexist with detergent monomers.

Figure 4. Schematic representation of different structures that may occur during the membranolytic process, i.e. the transition from liposome vesicles to mixed micelles (the different structures are described in the text).

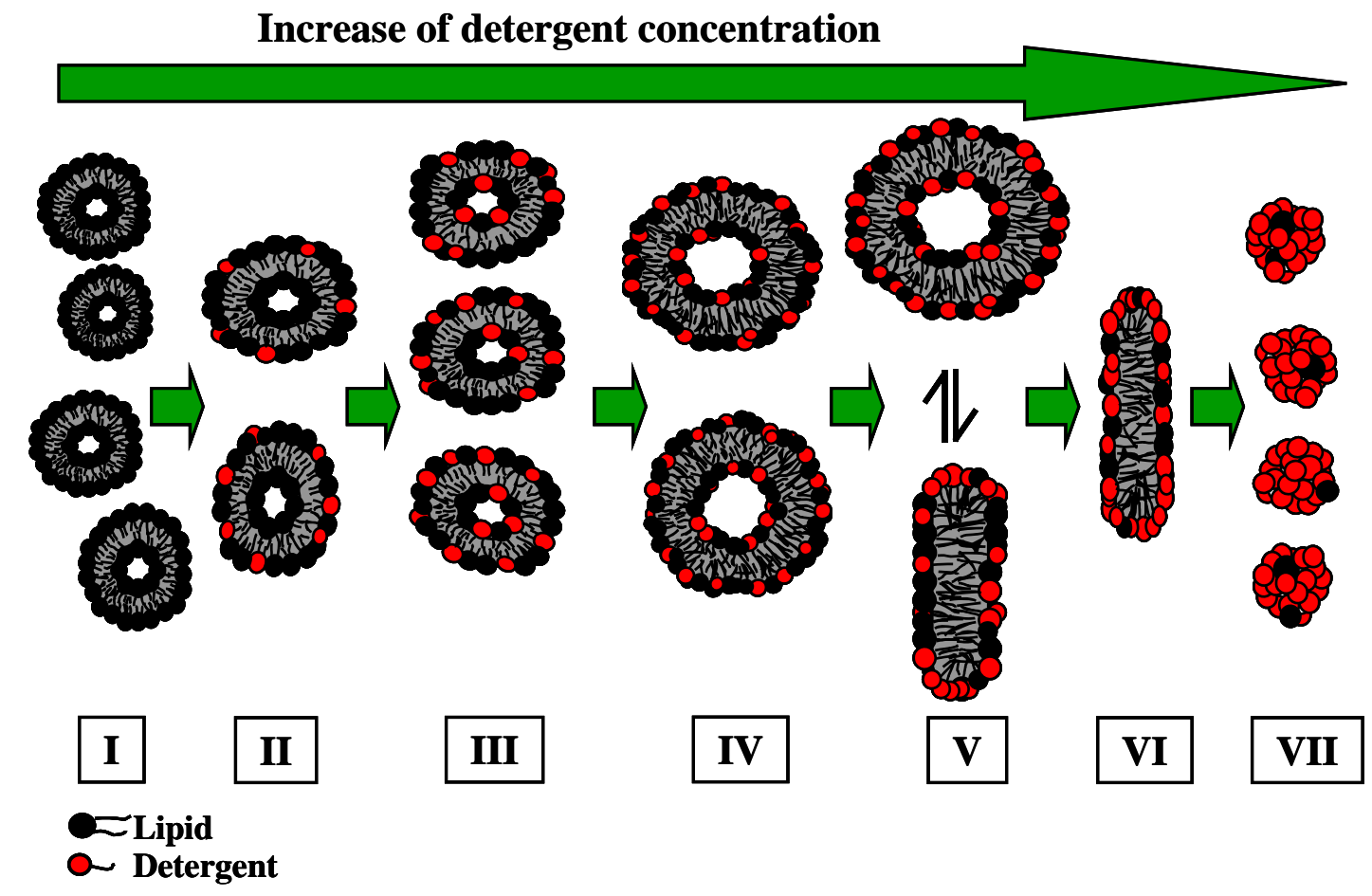


Thus, the addition of high concentrated detergent solutions to lipid dispersions results in the phase transition of liposomes into mixed micelles, the so-called 'solubilisation' process (Figure 2). A typical solubilisation experiment is shown in Figure 5. A highly concentrated detergent solution is titrated to a liposome dispersion. Under the chosen experimental conditions the first injections induce a continuous endothermic course (Figure 5, range I) in the heat flow versus time run.

In this range the detergent concentration in the cell remains lower than the critical concentration for membrane solubilisation. Thus, the peaks observed in Figure 5, range (I), are caused by the demicellisation process of the pure micelles, followed by the incorporation of the monomers into the lipid membrane. The observed heat flow is induced by the sum of the demicellization enthalpy and the partitioning enthalpy of the detergent monomers from water to the lipid membrane, the latter multiplied by the fraction of detergent molecules partitioning into the bilayers. In the further course of the solubilisation experiment a sudden change of the enthalpic effects from endothermic to exothermic is observed (Figure 5, range II). At the beginning of this range the free concentration of detergent in the cell reaches a critical concentration at which the bilayer membrane becomes saturated with detergent molecules and is unable to incorporate more detergent in the bilayer. At this concentration $D_{\mathrm{t}}^{\text {sat }}$ the detergent saturated mixed vesicles start to disintegrate and form mixed lipid detergent micelles.

With increasing detergent concentration amounts this equilibrium is shifted towards the mixed micelle structure. As can be seen from Figure 5, the observed reaction enthalpies are constant in this region (denoted by II in Figure 5). This is in agreement with the phase rule approximation, which predicts that the reaction enthalpies are constant over the whole coexistence range.

Figure 5. Schematic representation of a solubilisation experiment representing the titration of a micellar detergent solution into a liposomal dispersion. The experimental conditions were chosen so that complete solubilisation of the membrane occurs. Endotherm / exotherm reaction: describes a process or reaction that absorbs / releases energy in the form of heat.

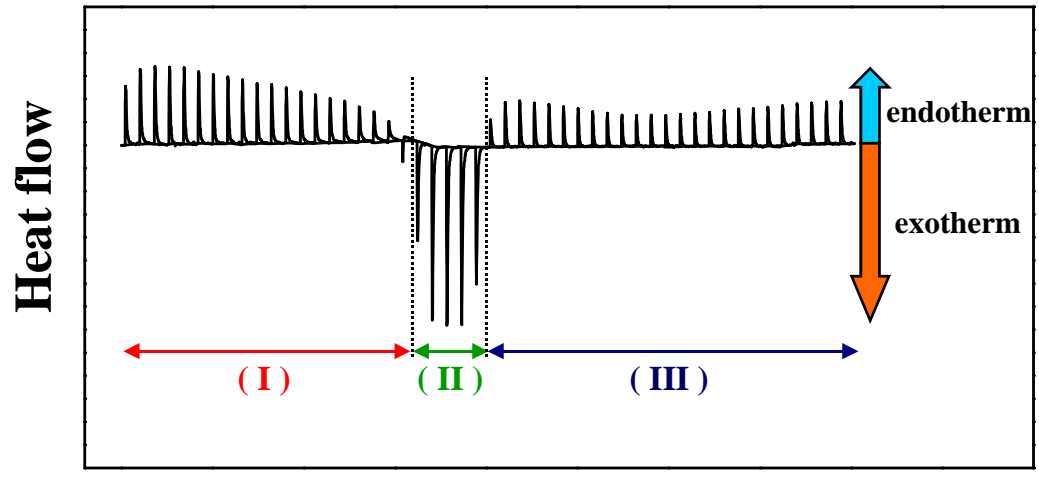

\section{Time}

Further titration of detergent induces a second drastic change in the heat flow versus time run, and much smaller endothermic peaks are observed at the end of the titration (Figure 5, range III). During the titration experiment the second phase boundary detected corresponds to the complete disintegration and transformation of mixed vesicles to mixed micelles. Above this concentration only mixed micelles are present in the sample in coexistence with detergent monomers. 
The phase boundaries of the membrane-to-micelle transition $D_{\mathrm{t}}^{\#}$ ('\#' means 'sat' or 'sol' for saturation and solubilisation) are shown in Figure 2 as straight lines (blue line: saturation, red line: solubilisation) [59, 72, 73]. The morphology of the formed aggregates depends on the chemical structure of the components, however, the composition of the mixed aggregates is given by the effective (index e) detergent to lipid ratio $R_{\mathrm{e}}{ }^{\#}$ according to:

$$
R_{\mathrm{e}}^{\#}=\frac{D_{\mathrm{b}}^{\#}}{L}
$$

The intercepts of the straight lines correspond to the hypothetical detergent concentrations $D_{\mathrm{w}}{ }^{\#}$ in the presence of lipid. This linear relationship is expressed by [27, 62, 74]:

$$
D_{t}^{\#}=R_{e}^{\#} \cdot L+D_{w}^{\#}
$$

The proposed approach considers that the composition induced transition between liposomes and micelles is solely determined by the detergent to lipid ratio within the aggregates and is independent of the aqueous absolute concentration of the amphiphiles. The described model (Equation 13) is adequate to represent the experimental phase boundaries for fairly high lipid concentrations. However, for low lipid concentrations deviations from linearity have been observed, especially at low lipid concentration $(<2 \mathrm{mM})$. Roth and co-workers have developed a model taking this discrepancy into account [75]. They have considered the effects of finite size of the threadlike micelles on the phase behaviour of the system. The liposomal phase and the aqueous detergent monomer solution is treated as described above, however, a more complex thermodynamic description of the micelles is used. The cylindrical parts and inhomogeneous end-caps (inhomogeneous with regards to detergent and lipid distribution compared to the distribution within the cylindrical part of the micelle) are considered, in analogy to the Gibbs treatment of interfaces [77, 78]. Using the Gibbs approach and considering the translational entropy of micelles, Roth et al. [75] determined the chemical potentials of the lipid and detergent in the micellar phase. Based on this they were able to derive equations, which describe the phase boundaries more adequate for low lipid concentrations [75]:

$$
D=D_{w}^{*}+\left[\alpha R^{\text {sol }}+(1-\alpha) R^{\text {sat }}\right] \cdot L-\frac{A_{\mathrm{w}}}{\alpha^{0.5} L^{0.5}}
$$

where $D$ is the detergent concentration for $L \rightarrow 0$ (intercept of the phase boundaries to one point), $\alpha$ the ratio between the concentration of the lipid in micellar form and the total lipid concentration, $A_{\mathrm{w}}$ a fitting parameter taking into account the scission energy (for more details see equation 45 in [75]).

The solubilisation phase boundary, which corresponds to complete transformation of the mixed vesicles into mixed micelles is characterised by $\alpha=1$, i.e. all lipid is incorporated in mixed micelles.

The corresponding phase boundary is given by:

$$
D=D_{w}^{*}+R^{\text {sol }} \cdot L-\frac{A_{w}}{L^{0.5}}
$$

For the lower phase boundary most of the lipid is found in the liposomal phase, thus $\alpha$ has to be small. Within the model chosen by Roth et al. [75], $\alpha$ is not allowed to be too small, because the approach adopted is just valid when the micelles are still sufficiently long, requiring a certain nonvanishing fraction of the lipid being in micelles. Assuming $\alpha_{\min }<<1$ in Equation 14, the equation for the saturation phase boundary is: 


$$
D=D_{w}{ }^{*}+R^{\mathrm{sat}} \cdot L-\frac{A_{\mathrm{w}}}{\alpha_{\min }^{0.5} L^{0.5}}
$$

The third term in Equations 15 and 16 accounts for the finite size of the micelles and determines the deviations of both phase boundaries from the straight line (described by Equation 13). As mentioned above, for high lipid concentrations these corrections can be neglected, while for low lipid concentrations they have a strong impact on the shape of the phase boundaries. The model by Roth et al., however, does not explain the difference between the intercepts $\left(D_{\mathrm{w}}^{\text {sat }} \neq D_{\mathrm{w}}^{\text {sol }}\right)$ as observed experimentally. More details cannot be given here, and it is recommended to consult [75] and references therein.

\section{Results and Discussion}

Isothermal titration calorimetry (ITC) was used for the characterisation of the interaction of the bile salt detergents sodium cholate and sodium deoxycholate with model membranes. The liposomes were prepared from phosphatidylcholines (PCs) with saturated acyl chains of different length (C14: 1,2-dimyristoyl-sn-glycero-3-phosphatidylcholine, DMPC, and C16: 1,2-dipalmitoyl-sn-glycero-3phosphatidylcholine, DPPC), unsaturated fatty acids (1-palmitoyl-2-oleoyl-sn-glycero-3phosphatidylcholine, POPC) and of a natural occurring PC source composed of lipids with mainly unsaturated acyl chains (soybean phosphatidylcholine, SPC). Under physiological conditions, PCs are zwitterionic. Hence, to analyse the influence of membrane surface charge density with regard to membranolytic activity of the detergents, membranes were prepared with a lipid, which under physiological conditions is negatively charged (1,2-dipalmitoyl-sn-glycero-3-phosphatidyl-glycerol, DPPG) [54, 76]. Different DPPC to DPPG mixtures were prepared in order to modulate the surface charge.

Using ITC, the partition coefficients $P$ were determined as well as the transfer enthalpy $\Delta H^{\mathrm{T}}$ for the detergent from water to the bilayer phase. The partition experiments were performed as shown in Figures 2 and 3A (for more details see Experimental section). The partition coefficients were calculated using a model, which takes into account electrostatic interactions (see above). The membranolytic effect was assessed in a so-called solubilisation experiment, where a certain amount of detergent is added to the liposomal dispersion up to the complete disruption of the membrane and the formation of mixed micelles composed of a large excess of detergent and smaller amounts of lipid. This process is investigated by ITC and DLS. Based on the results from ITC, thermodynamic parameters are determined for the solubilisation process of the lipid membranes. The phase boundaries for the vesicle-to-micelle phase transition are determined from ITC or alternatively from DLS experiments.

\section{Influence of bile salt hydrophobicity}

Based on the chemical nature of $\mathrm{NaDC}$ and $\mathrm{NaC}$, the hydrophobicity of the former bile salt is higher because it has only two hydroxyl groups compared the $\mathrm{NaC}$ with three hydroxyl groups (see Figure 1). As a consequence the solubility and the aggregation properties are quite different [23, 24]. The $\mathrm{cmc}$ in water at $\mathrm{pH} 7.5\left(25^{\circ} \mathrm{C}\right)$ is $15 \mathrm{mM}$ for $\mathrm{NaC}$ and $6 \mathrm{mM}$ for $\mathrm{NaDC}$ [79]. The influence of the 
bile salt hydrophobicity with regards to the bile salt partitioning into lipid membranes at $60{ }^{\circ} \mathrm{C}$ in water is represented in Figure 6. The temperature was chosen in order to make sure that the experiments are performed for both lipid systems in the liquid crystalline phase [54, 64]. As can be seen from Figure 6, there is a clear difference in the partitioning behaviour between the two bile salts. The titration of $\mathrm{NaC}$ shows a titration curve with a continuous change in the reaction heats.

However, the titration curve of $\mathrm{NaDC}$ is characterised by a discontinuous shape in the $Q$ versus $L$ course leading to the assumption that the interaction of $\mathrm{NaDC}$ with the membranes appears to be a two-step process. At the beginning of the titration the reaction heat $Q$ decreases much more for NaDC with increasing the lipid concentration compared to $\mathrm{NaC}$. For the later injections a weaker reaction heat decrease is observed as a function of lipid titration. For $\mathrm{NaC}$ the partition curve indicates a onestep process. Therefore, the experimental and calculated data (calculated with the model presented above) agree much better for $\mathrm{NaC}$ compared to NaDC.

Figure 6. Partition experiment: Titration of a lipid dispersion (syringe) of a concentration of $20 \mathrm{mM}$, DPPC (top) and SPC (bottom), into a $\mathrm{NaC}(10 \mathrm{mM})$ or $\mathrm{NaDC}(4 \mathrm{mM})$ solutions in water at $T=60{ }^{\circ} \mathrm{C}(p H 7.5)$. Injection scenario: 50 injections à $5 \mu \mathrm{l}$. The plots represent the change in reaction heat $Q$ of each injection versus lipid concentration $L$ in the cell (adapted from [56, 59]). The full lines were obtained from simulations using the partition model described in the text.
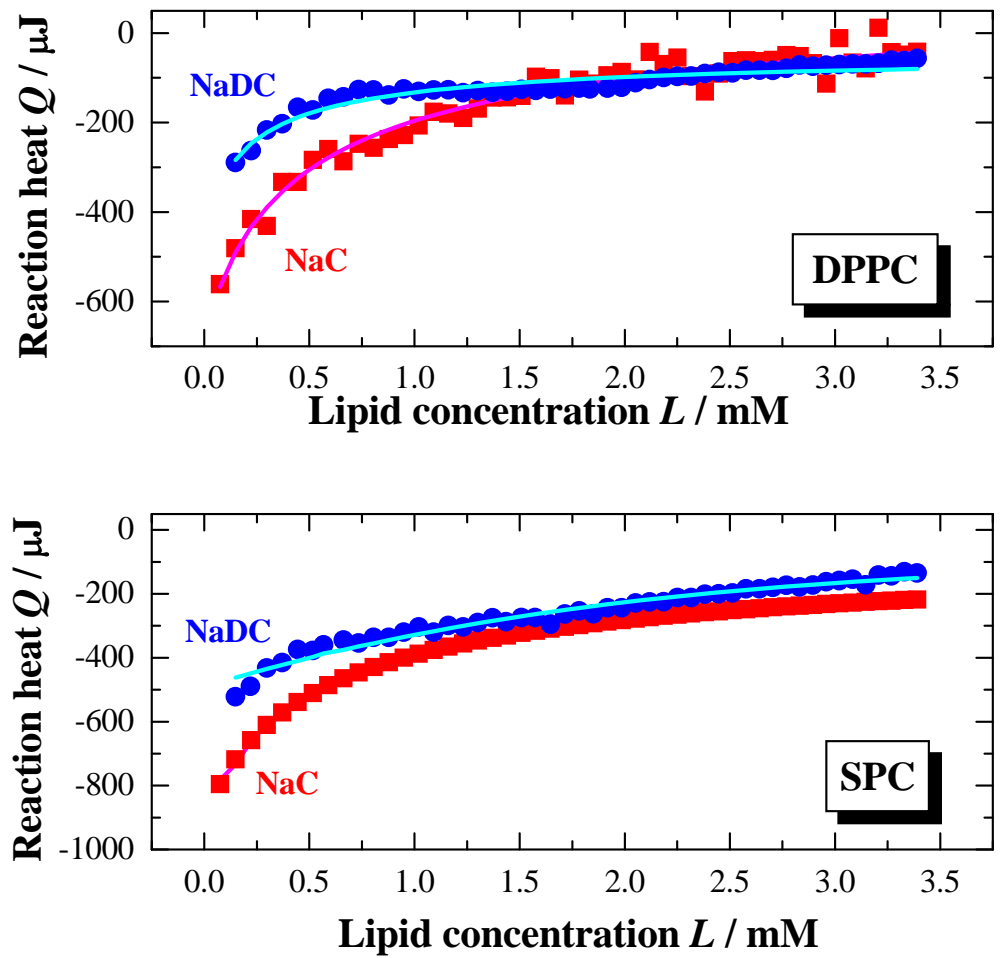

Under the chosen experimental conditions, exotherm reaction heats are obtained (Figure 6). The transfer enthalpies $\Delta H^{\mathrm{T}}$ are negative for the transfer of bile salt monomers from the aqueous to the lipid phase. For the examined lipid systems, it is observed that $\Delta H^{\mathrm{T}}(\mathrm{NaC})<\Delta H^{\mathrm{T}}(\mathrm{NaDC})$. Compared to the detergent transfer enthalpy from water to a detergent micelle, where $\Delta H^{\mathrm{T}}$ values of $-8 \mathrm{~kJ} \cdot \mathrm{mol}^{-1}$ 
(NaC) and $-13 \mathrm{~kJ} \cdot \mathrm{mol}^{-1}$ (NaDC) are obtained [79], the transfer enthalpies to a lipid phase are much smaller.

The partition coefficients presented in this study are given in mole fraction units. $P_{0}$ is the intrinsic partition coefficient, and $P_{\mathrm{av}}$ represents the partition coefficient in the "middle" of the titration experiment (Table 2).

A strong dependency of the hydrophobicity of the bile salts is seen in the partition coefficients. Comparing the two reported partition coefficient show that $P(\mathrm{NaC})<<P(\mathrm{NaDC})$, indicating that $\mathrm{NaDC}$ is easier incorporated in the membrane.

Analysing the change in Gibbs free energy $\Delta G^{\mathrm{T}}$ for the micellisation process indicates values in the range of -20 to $-26 \mathrm{~kJ} \cdot \mathrm{mol}^{-1}$, whereas much more negative values are detected for the detergent monomer transfer to a lipid membrane (Table 2). As can be seen from Table 2, the Gibbs free energy change varies with the presence of detergent amount; a decrease is observed with increasing the detergent concentration in the lipid phase. The reasons for this effect are twofold. First, with increasing presence of detergent, the membrane surface charge increases, and as a consequence, as described by the Gouy-Chapman model, a decrease in the concentration of the detergent molecules in the vicinity of the membrane is induced. The apparent partitioning coefficient $P_{\text {app }}$ decreases therefore at each titration step, whereas the intrinsic partitioning coefficient $P_{0}$, which does not consider electrostatic effects, is a constant. Second, non-ideal mixing of the bile salt detergent with the lipid molecules has to be considered, leading to a non-zero non-ideality coefficient $(\rho)$. A $\rho \neq 0$ will also decrease the partition coefficient (see Equation 4).

Table 2. Thermodynamic parameters for the partitioning of $\mathrm{NaC}$ and $\mathrm{NaDC}$ into DPPC and SPC membranes dispersed in water at $p H 7.5$ at $60{ }^{\circ} \mathrm{C}$ (liquid crystalline phase). The thermodynamic values are given in $\mathrm{kJ} \cdot \mathrm{mol}^{-1}[56,59]$.

\begin{tabular}{|c|c|c|c|c|c|c|c|}
\hline System & $\Delta H^{T}$ & $\Delta G_{0}^{T}$ & $\Delta G_{\mathrm{av}}^{\mathrm{T}}$ & $T \cdot \Delta S_{0}^{\mathrm{T}}$ & $T \cdot \Delta S_{\mathrm{av}}^{\mathrm{T}}$ & $P_{0} \times 10^{6}$ & $P_{\mathrm{av}} \times 10^{3}$ \\
\hline NaC/DPPC & -1.2 & -43.4 & -24.8 & 42.2 & 23.6 & 6.4 & 7.8 \\
\hline $\mathrm{NaC/SPC}$ & -1.6 & -43.6 & -24.9 & 42.0 & 23.4 & 6.9 & 8.1 \\
\hline NaDC/DPPC & -0.7 & -48.7 & -35.0 & 48.1 & 34.4 & 44 & 310 \\
\hline $\mathrm{NaDC} / \mathrm{SPC}$ & -0.4 & -48.6 & -35.1 & 48.2 & 34.7 & 43 & 319 \\
\hline
\end{tabular}

The difference in the partition coefficient between the two bile salts reflects also the membranolytic activity of the detergent. The lipid to detergent phase diagrams for NaDC and $\mathrm{NaC}$, representing the solubilisation of the membrane are shown in Figure 7. In general, the amount of detergent required for the saturation and solubilisation of the membrane is different for the two bile salts. For the solubilisation of e.g. DPPC membranes at least two times more $\mathrm{NaC}$ is needed compared to NaDC. The detergent concentration where membrane solubilisation occurs depends on the total lipid amount. For higher lipid concentrations, the detergent concentration needed is higher than the cmc [79, 80]. The composition of the aggregates formed at the saturation solubilisation phase boundary is given by the effective detergent to lipid ratios $R_{\mathrm{e}}$, which are summarised in Table 3. $R_{\mathrm{e}}^{\text {sat }}$ 
(NaC) is in general smaller compared to $R_{\mathrm{e}}{ }^{\text {sat }}$ (NaDC). This is still the case for $R_{\mathrm{e}}{ }^{\text {sol }}(\mathrm{NaC})$, however the difference become smaller. Comparing these $R_{\mathrm{e}}$ data with data reported for non ionic detergents like OG [25, 28], shows that for ionic detergents $R_{\mathrm{e}}$ data at least one order of magnitude higher. The extremely low $R_{\mathrm{e}}$ data for bile salts indicate the saturation limit being reached at very low effective detergent concentration in the membrane, and thus reflects the high membranolytic potential. This is more pronounced for the more hydrophobic bile salt.

Table 3. NaC and NaDC solubilisation data for DPPC and SPC in water ( $p H 7.5)$ at $60{ }^{\circ} \mathrm{C}$. $R_{\mathrm{e}}$ : slopes of the saturation (sat) and solubilisation (sol) process, $D_{\mathrm{w}}$ : equilibrium bile salt concentration. Values reported in parentheses are obtained using the model proposed by Roth et al. [75].

\begin{tabular}{|c|c|c|c|c|}
\hline System & $\boldsymbol{R}_{\mathbf{e}}^{\text {sat }}$ & $\boldsymbol{R}_{\mathbf{e}}^{\text {sol }}$ & $\boldsymbol{D}_{\mathbf{w}}^{\text {sat }} / \mathbf{m M}$ & $\boldsymbol{D}_{\mathbf{w}}^{\text {sol }} / \mathbf{~ m M}$ \\
\hline $\mathrm{NaC} / \mathrm{DPPC}$ & $0.11(0.022)$ & $0.15(0.13)$ & $16.5(18)$ & $17.8(18)$ \\
\hline $\mathrm{NaC} / \mathrm{SPC}$ & 0.48 & 0.96 & 19.4 & 32.3 \\
\hline $\mathrm{NaDC} / \mathrm{DPPC}$ & $0.21(0.082)$ & $0.23(0.211)$ & $6.4(8)$ & $7.5(8)$ \\
\hline $\mathrm{NaDC} / \mathrm{SPC}$ & 1.02 & 1.25 & 4.7 & 9.9 \\
\hline
\end{tabular}

From Figure 7 and the data reported in Table 3 it is obvious that $D_{\mathrm{w}}^{\text {sat }} \neq D_{\mathrm{w}}^{\text {sol }}$ as expected by equation 13, and that the linearity described by equation 13 is also not given. Deviation from linearity is especially observed for lipid concentrations lower than $2 \mathrm{mM}$. The reason for this behaviour could be that below this concentration the equilibrium aggregation state becomes concentration dependent.

The initial 3 stage model describing the solubilisation of membranes involves no compositional changes of the coexisting aggregates throughout the complete coexistence range. Obviously this is not the case. Therefore, Roth et al. [75] have developed a model taking in consideration the finite size of the mixed micelles and the energetic effects of end-caps of cylindrical micelles. Using this model, deviations from linearity at low lipid concentrations can be better described. The calculated curves (according to Roth et al.) are represented in Figure 7 as dashed lines, and as can be seen, fit much better the experimental data. The corresponding data for the phase diagram using the Roth et al. approach are reported in Table 3 (values in parentheses).

The interaction properties of the two bile salts have also been investigated by DLS, in order to derive information with regards to the particles formed during solubilisation, and to complement the results derived from ITC. The presented example (Figure 8) shows the DLS-scattering intensity as a function of the hydrodynamic radius $R_{\mathrm{h}}$. In Figure 8 is exemplarily shown the titration of a $6 \mathrm{mM}$ DPPC dispersion in water $\left(p H 7.5,55^{\circ} \mathrm{C}\right)$ with a $150 \mathrm{mM} \mathrm{NaC}$ solution in water ( $p H$ 7.5) in steps of $20 \mu \mathrm{L}$.

The hydrodynamic radius of the pure DPPC vesicles is about $R_{\mathrm{h}} \approx 50 \mathrm{~nm}$, and shows a broad size distribution. The addition of bile salt induces a decrease of the hydrodynamic radii. In the mixed vesicular range for the system DPPC/NaC a decrease to $R_{\mathrm{h}} \approx 25 \mathrm{~nm}$ is detected.

The coexistence region is characterised by the presence of larger aggregates of a size in the range $R_{\mathrm{h}} \approx 15 \mathrm{~nm}$ and much smaller aggregates of $R_{\mathrm{h}} \approx 1.5 \mathrm{~nm}$. The aggregate size in the mixed micellar 
region further decreases upon increasing the presence of bile salt. A more or less constant aggregate size of $R_{\mathrm{h}} \approx 1.5 \mathrm{~nm}$ is obtained at the end of the titration for both systems $\mathrm{DPPC} / \mathrm{NaC}$ and $\mathrm{DPPC} / \mathrm{NaDC}$.

Based on the DLS results the phase boundaries with the characteristic data $D_{\mathrm{t}}^{\text {sat }}$ and $D_{\mathrm{t}}^{\text {sol }}$ can be obtained and are compared to the data derived from ITC. Both values correspond very well. The DLS data confirm that the amount of the more hydrophilic bile salt $\mathrm{NaC}$ is higher compared to the higher membranolytic potential of NaDC.

Figure 7. Phase diagrams for the vesicle-to-micelle transition (membrane solubilisation) in $\mathrm{NaC} / \mathrm{DPPC}, \mathrm{NaDC} / \mathrm{DPPC}, \mathrm{NaC} / \mathrm{SPC}$ and NaDC/SPC in water $(p H 7.5)$ at $T=60{ }^{\circ} \mathrm{C}$. Phase boundaries are represented by the experimentally obtained data $D_{\mathrm{t}}^{\text {sat }}$ (open symbols) and $D_{\mathrm{t}}^{\text {sol }}$ (closed symbols). Solid lines: phase boundaries calculated according to equation 13, dashed lines: phase boundaries calculated according Roth et al. [75].
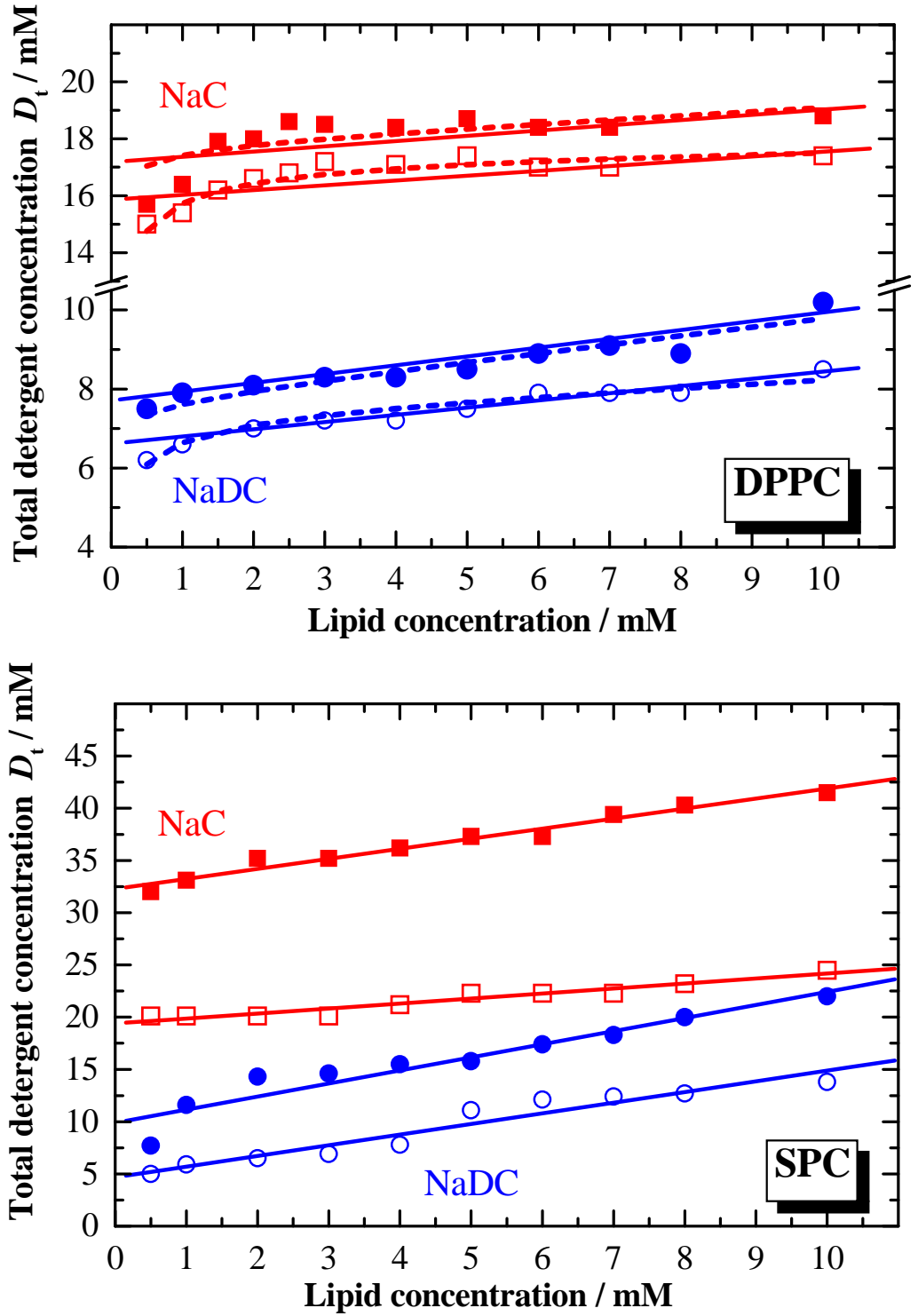
Figure 8. Results of DLS (dynamic light scattering) solubilisation experiments: Solubilisation of DPPC vesicles at $6 \mathrm{mM}$ dispersed in water $(p H 7.5)$ with $\mathrm{NaC}$ at a concentration of $150 \mathrm{mM}$ at $T=55^{\circ} \mathrm{C}$. Titration volume: $20 \mu \mathrm{L} \mathrm{NaC}$.

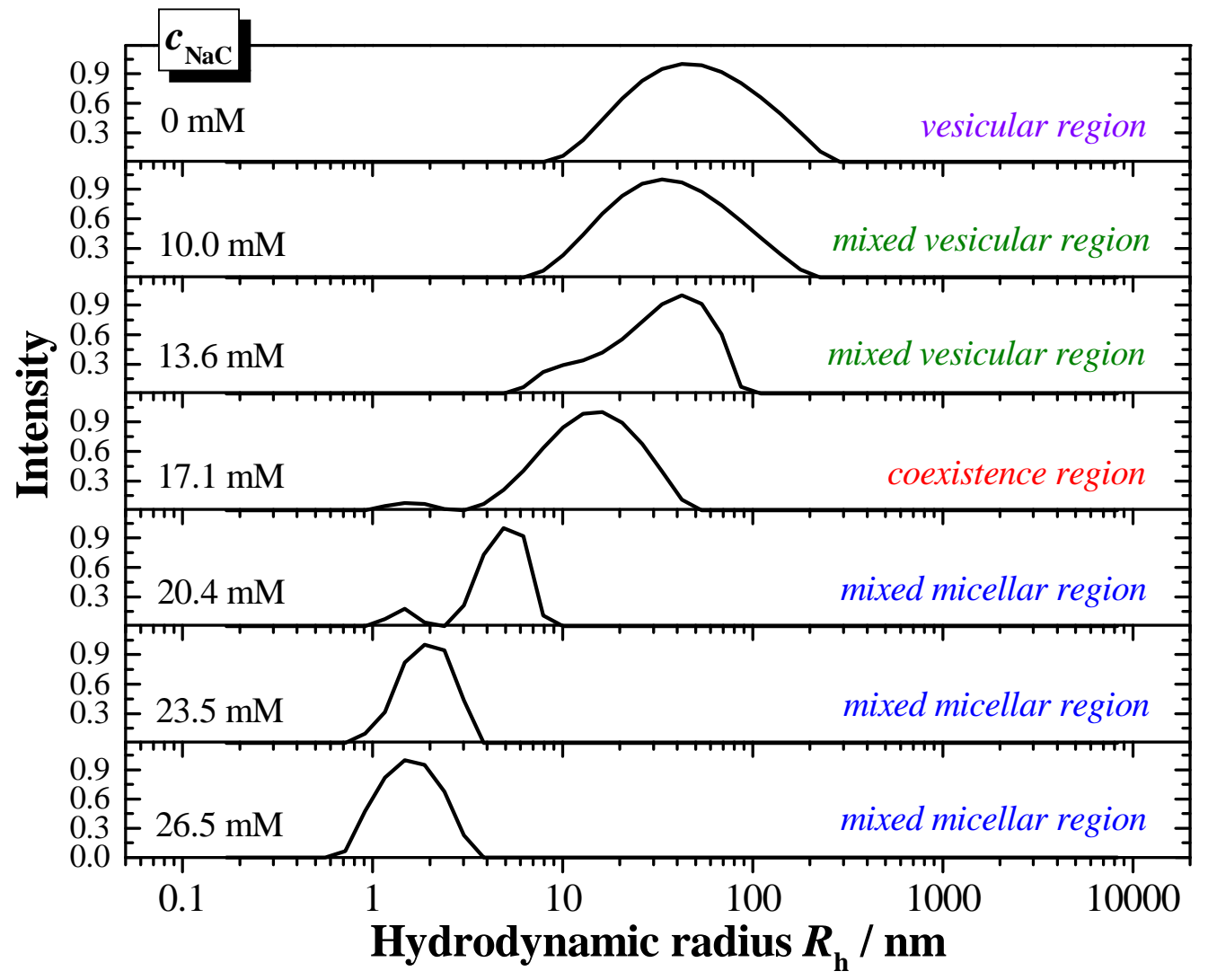

Influence of ionic strength

Increasing the ionic strength induces a screening of the negative charge of the bile salts. As a consequence they become more "hydrophobic"; the $\mathrm{cmc}$ of e.g. $\mathrm{NaC}$ in water $\left(p H 7.5,25{ }^{\circ} \mathrm{C}\right)$ decreases from $15 \mathrm{mM}$ to $11.5 \mathrm{mM}$ for an increase of the ionic strength to $100 \mathrm{mM} \mathrm{NaCl}$ ( $p H$ 7.5, 25 $\left.{ }^{\circ} \mathrm{C}\right)$.

The transfer enthalpies $\Delta H^{\mathrm{T}}$ become more negative with increasing the ionic strength. For the system NaDC/DPPC $\left(60^{\circ} \mathrm{C}, p H\right.$ 7.5) $\Delta H^{\mathrm{T}}\left(\mathrm{H}_{2} \mathrm{O}\right)=-0.7 \mathrm{~kJ} \cdot \mathrm{mol}^{-1}$ and for $\Delta H^{\mathrm{T}}(100 \mathrm{mM} \mathrm{NaCl})=-6.7$ $\mathrm{kJ} \cdot \mathrm{mol}^{-1}$.

Additionally, increasing the ionic strength should increase the bile salt partition coefficient, because the charges are screened to a large extent reducing the electrostatic effects. This is observed. Higher $P_{\text {av }}$ values and larger $\Delta G_{\text {av }}{ }^{\mathrm{T}}$ are obtained in $100 \mathrm{mM} \mathrm{NaCl}$ compared to pure water. The intrinsic partition coefficient should be unaffected by changing the ionic strength, due to the fact that charge screening effects at infinite dilution of the bile salt in the lipid phase is strongly reduced (for more details see $[41,56,59,62])$.

In the presence of ions the detergent concentration for the saturation and solubilisation of membranes (Figure 9) is drastically reduced, as can be seen by comparing the corresponding $D_{\mathrm{w}}{ }^{\#}$ values (see Tables 3 and 4). 
Figure 9. Solubilisation experiment: Titration of a micellar NaDC solution (50 mM) into a DPPC dispersion (6 mM) in $0.1 \mathrm{M} \mathrm{NaCl}, p H 7.5$ at $60^{\circ} \mathrm{C}$ with 50 x $5 \mu \mathrm{l}$.

(A) Calorimetric traces, (B) normalised titration heat $Q$ versus total detergent concentration in the cell $D_{\mathrm{t}}$, (C) first derivative of curve (B).
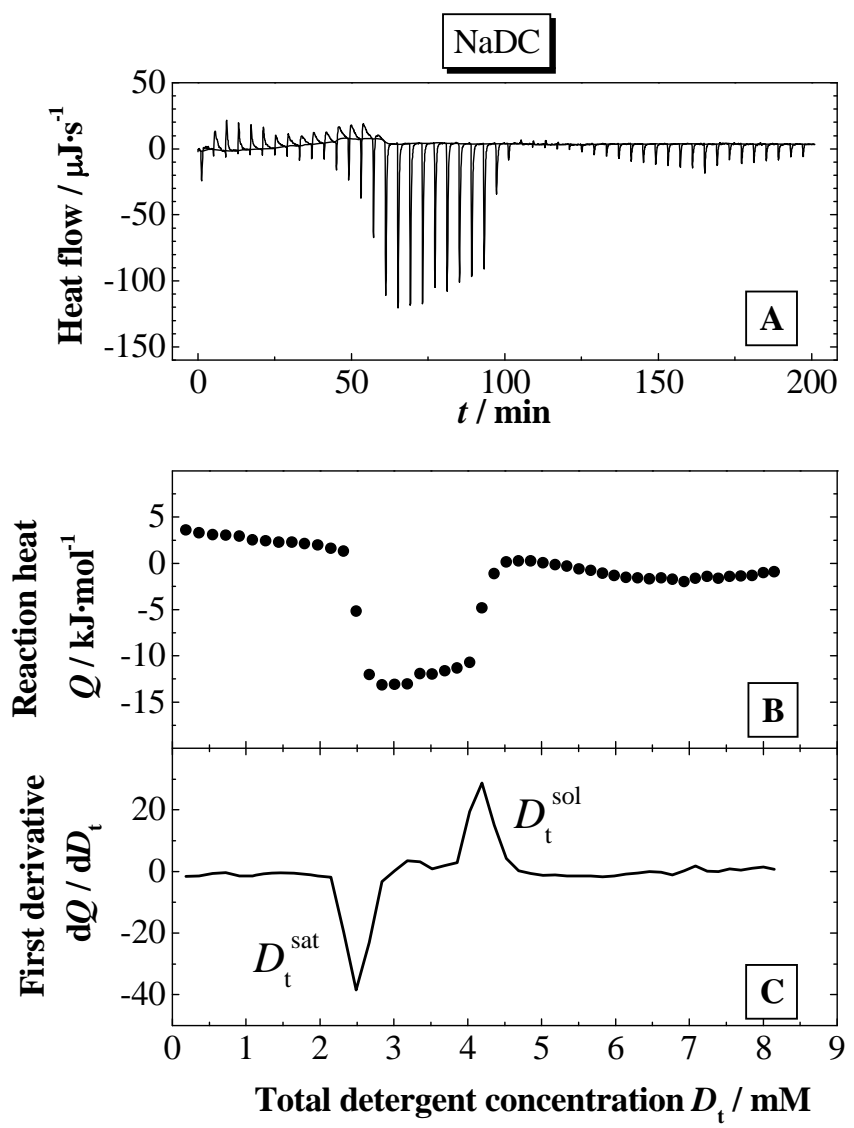

The composition of the mixed vesicles as well as the mixed micelles shows in general larger $R_{\mathbf{e}}^{\#}$ values, indicating that more detergent is incorporated in the aggregates as the ionic strength increases. The detergent amount required for saturation and solubilisation of the phospholipid membranes is dramatically reduced for both bile salts in the presence of salt. The system NaC/DPPC at $60{ }^{\circ} \mathrm{C}$ shows with increasing the ionic strength from water to $100 \mathrm{mM} \mathrm{NaCl}$ a decrease of $D_{\mathrm{w}}{ }^{*}$ by about $60 \%$.

The phase diagrams for the vesicle-to-micelle transition in water (Figure 7) are characterised by non-linear phase boundaries with a decrease of the phase boundaries at low lipid concentration [59, 62, $75,81]$. This is not observed to such an extent for the lipid to bile salt systems dispersed in $100 \mathrm{mM}$ $\mathrm{NaCl}$. These results are confirmed by the analysis of the DLS titration experiments (data not shown). However, based on DLS no exact information with regards to the shape of the formed aggregates can be obtained. Therefore, SANS measurements were performed [82-84]. This is exemplarily described for the system $\mathrm{NaDC} / \mathrm{DPPC}$ in $100 \mathrm{mM} \mathrm{NaCl}$ at $60{ }^{\circ} \mathrm{C}$. Various amounts of detergent $(1.5-10 \mathrm{mM})$ were added to a constant amount of DPPC (6 mM) dispersion. The corresponding scattering plots are shown in Figure 10. The interpretation of the SANS data is performed according to the Guinier analysis [82, 83, 85]. In brief: the exponent of the scattering vector $q$, the so-called $q$-domain, contains information of the aggregate type. A $q^{-2}$ is an indication for the scattering of vesicles, whereas $q^{-1}$ is 
due to scattering of longitudinal aggregates, like cylindrically shaped micelles. A $q^{0}$ is a characteristic for spherical micelles.

Table 4. NaC and NaDC solubilisation data for DPPC and SPC in 100 $\mathrm{mM} \mathrm{NaCl}(p H 7.5)$ at $60{ }^{\circ} \mathrm{C}$. $R_{\mathrm{e}}$ : slopes of the saturation (sat) and solubilisation (sol) process, $D_{\mathrm{w}}$ : equilibrium bile salt concentration.

\begin{tabular}{|c|c|c|c|c|}
\hline System & $\boldsymbol{R}_{\mathbf{e}}{ }^{\text {sat }}$ & $\boldsymbol{R}_{\mathbf{e}}{ }^{\text {sol }}$ & $\boldsymbol{D}_{\mathbf{w}}{ }^{\text {sat }} / \mathbf{m M}$ & $\boldsymbol{D}_{\mathbf{w}}{ }^{\text {sol }} / \mathbf{m M}$ \\
\hline $\mathrm{NaC} / \mathrm{DPPC}$ & 0.19 & 0.29 & 5.6 & 6.6 \\
\hline $\mathrm{NaC} / \mathrm{SPC}$ & 0.45 & 0.91 & 7.9 & 11.2 \\
\hline $\mathrm{NaDC} / \mathrm{DPPC}$ & 0.20 & 0.39 & 1.4 & 1.7 \\
\hline $\mathrm{NaDC} / \mathrm{SPC}$ & 0.29 & 0.82 & 2.2 & 2.9 \\
\hline
\end{tabular}

The SANS data for a mixture composed of $6 \mathrm{mM}$ DPPC and $1.5 \mathrm{mM}$ NaDC (mixture in the mixed vesicular range, below the coexistence curve for the saturation process) forms aggregates which would fit for a model aggregate system of ellipsoidal shape (Figure 10A).

At detergent concentrations between 3.5 and $7.5 \mathrm{mM}$ more complex scattering patterns are obtained, which were analysed according to Guinier [82]. A mixture composed of 6 mM DPPC and 3.5 $\mathrm{mM} \mathrm{NaDC}$ forms a composition, which is found in the coexistence range of the vesicle-to-micelle transition. The SANS data can be divided in two q-regions, which corresponds to the scattering properties as observed for flexible, polymer like micelles [82]. The calculated persistence length is $l_{\mathrm{p}}=$ $19 \mathrm{~nm}$, which is in good agreement with literature data by Petersen et al. [86] who reported $l_{\mathrm{p}}=18 \mathrm{~nm}$.

The cylindrical micelles formed have dimensions of $a=3.3 \mathrm{~nm}$ and $b=2.1 \mathrm{~nm}$. Increasing the amount of detergent e.g. to $5.5 \mathrm{mM} \mathrm{NaDC}$ induces the formation of aggregates composed of cylindrical and ellipsoidal shapes. This is illustrated by $q^{-0.85}$ (Figure 10C). The cylindrical aggregates become more symmetric. The ellipsoidal micelles are characterised by $a=9.5 \mathrm{~nm}$ and $b=2.1 \mathrm{~nm}$, with an eccentricity of $\varepsilon=4.5$. These results are in accordance to the SANS data presented by Hjelm et al. [69]. At a detergent concentration of $7.5 \mathrm{mM}$ (Figure 10D) the evaluation of the SANS data yield a scattering vector with $q^{-0.19}$ which shows that the formed ellipsoidal aggregates are transformed to more spherical shaped micelles (both type of micelles are present) and at a detergent concentration of $10 \mathrm{mM}$ the fitted scattering vector of $q^{0}$ is indicative for the presence of spherical micelles. The micelle radius calculated is approximately $2.2 \mathrm{~nm}$ and more or less independent of the ionic strength [82]. The micelle radius determined by Hjelm et al. [69] was $2.5 \mathrm{~nm}$. Based on DLS measurements the hydrodynamic radius in the mixed micellar range was $\approx 1.5 \mathrm{~nm}$ and independent of the ionic strength, confirming the SANS data. 
Figure 10. SANS (small angle neutron scattering) distributions for the solubilisation of DPPC liposomes $(6 \mathrm{mM})$ by various amounts of $\mathrm{NaDC}$ in $0.1 \mathrm{M} \mathrm{NaCl}, p H 7.4$ at $60{ }^{\circ} \mathrm{C}$. (A) $c_{\mathrm{NaDC}}=1.5 \mathrm{mM}$, (B) $c_{\mathrm{NaDC}}=3.5 \mathrm{mM}$, (C) $c_{\mathrm{NaDC}}=5.5 \mathrm{mM}$, (D) $c_{\mathrm{NaDC}}=7.5 \mathrm{mM}$, and (E) $c_{\mathrm{NaDC}}=10 \mathrm{mM}$.

\section{A}
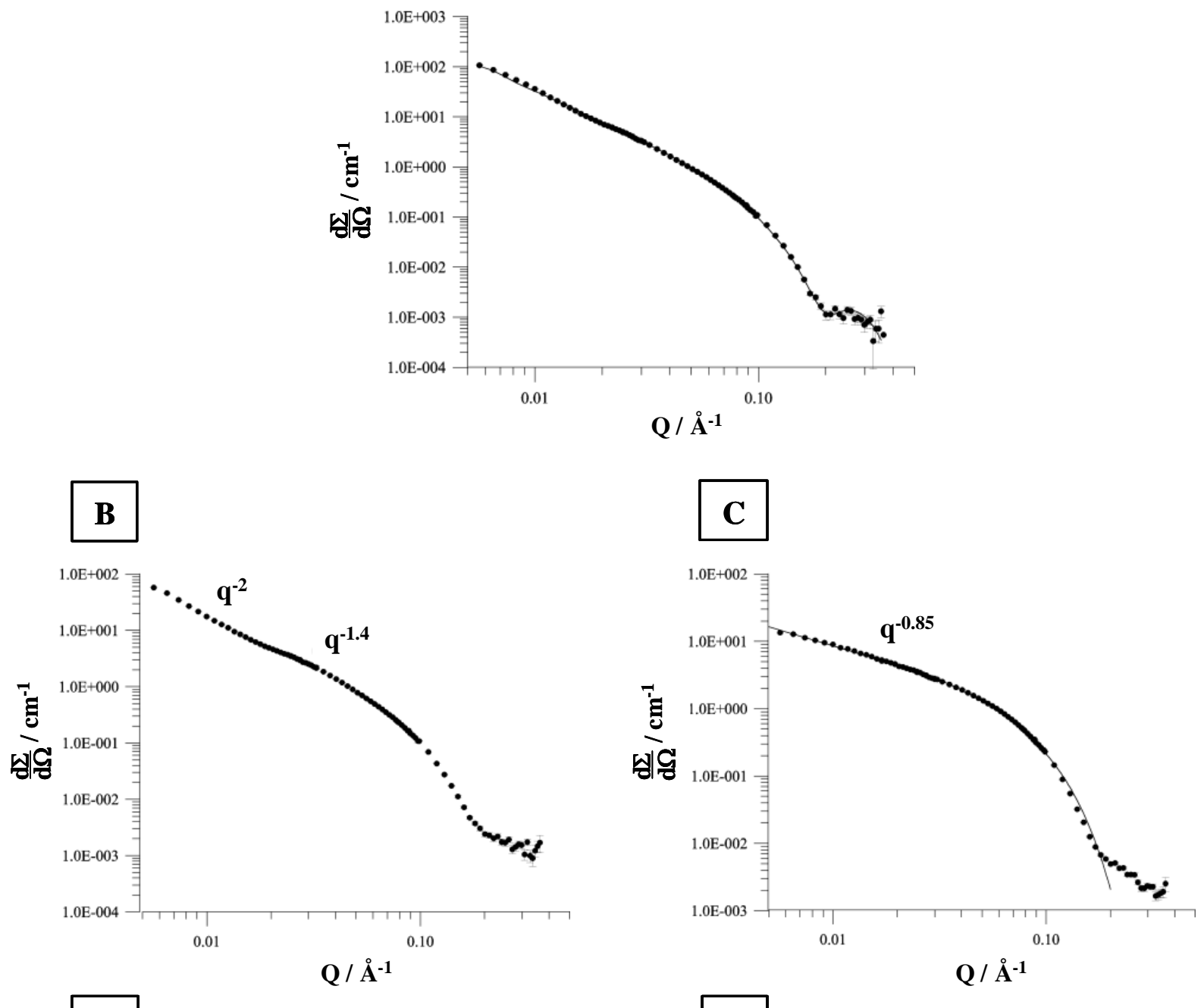

\section{D}

\section{$\mathbf{E}$}
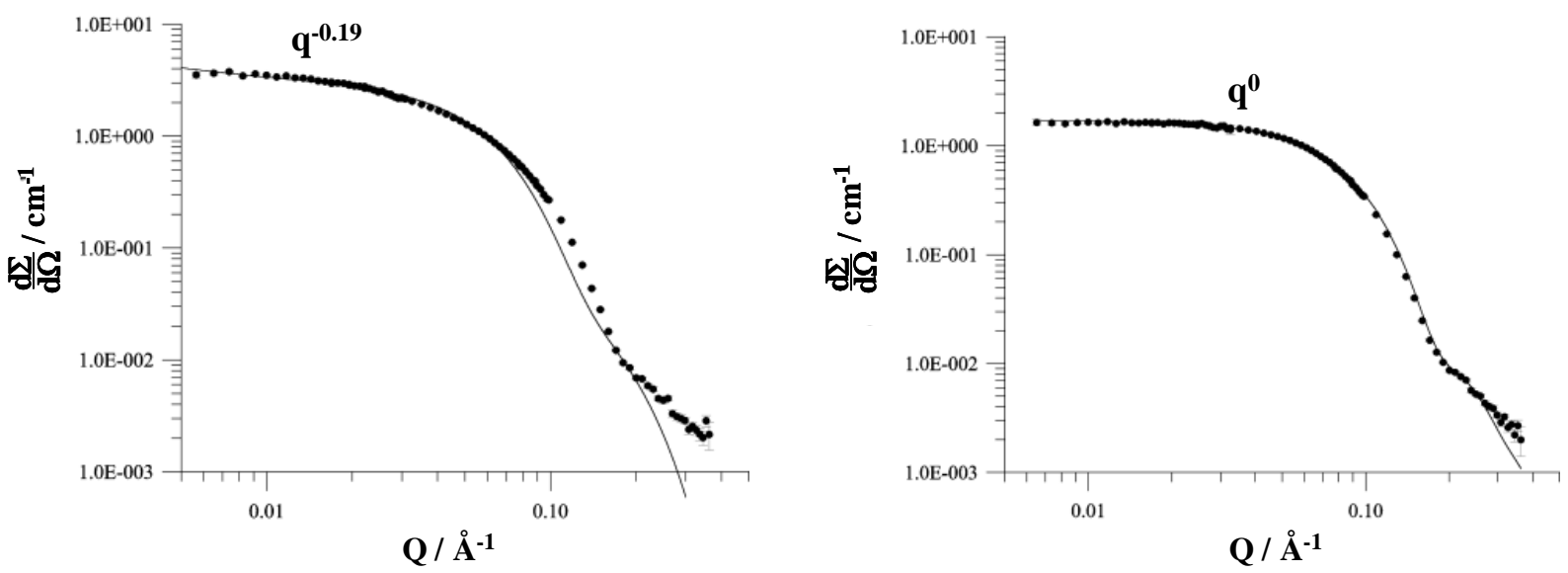


\section{Influence of temperature}

The influence of temperature over a temperature range between 20 and $60{ }^{\circ} \mathrm{C}$ was investigated for POPC and SPC. In this temperature range SPC stays in the liquid crystalline phase, because the main phase transition temperature of SPC is at $T_{\mathrm{m}} \approx-15{ }^{\circ} \mathrm{C}$ and for POPC at $T_{\mathrm{m}} \approx-3^{\circ} \mathrm{C}$.

The transfer enthalpies are negative for the transfer of detergent monomers from the aqueous to the lipid phase (Figure 3). Increasing the temperature induces in general more negative transfer enthalpies. The difference is maximal for the system NaDC/SPC dispersed in $100 \mathrm{mM} \mathrm{NaCl}(p H 7.5)$ with $\Delta H^{\mathrm{T}}\left(30^{\circ} \mathrm{C}\right)=-2.1 \mathrm{~kJ} \cdot \mathrm{mol}^{-1}$ and $\Delta H^{\mathrm{T}}\left(60^{\circ} \mathrm{C}\right)=-7.3 \mathrm{~kJ} \cdot \mathrm{mol}^{-1}$.

When the $\Delta H^{\mathrm{T}}$ data are compared, at the same temperature, for SPC and POPC, it becomes obvious that much more negative data are obtained for POPC. The reason for this seems to be the different fatty acid composition and distribution of the lipid (see below).

The temperature dependency of $\Delta H^{\mathrm{T}}$ allows the calculation of the change of heat capacity $\Delta C p=$ $\left(\partial \Delta H^{\mathrm{T}} / \partial T\right)_{\mathrm{p}}$, if a linear decrease in the transfer enthalpies as a function of temperature is assumed. The data are summarised in Table 5.

Table 5. Change of the heat capacity $\triangle C p$ for SPC and POPC detergent systems at low and high ionic strength.

\begin{tabular}{|c|c|c|c|}
\hline Detergent & Buffer & \multicolumn{2}{|c|}{$\Delta \mathbf{C p} / \mathbf{J}^{-\mathbf{1}} \cdot \mathbf{m o l}^{-\mathbf{1}}$} \\
\hline & & SPC & POPC \\
\hline $\mathrm{NaC}$ & Water, $p H 7.5$ & -29 & -46 \\
\hline $\mathrm{NaC}$ & $100 \mathrm{mM} \mathrm{NaCl}, \mathrm{pH} 7.5$ & -37 & -91 \\
\hline $\mathrm{NaDC}$ & Water, $p H 7.5$ & $\approx 0$ & -105 \\
\hline $\mathrm{NaDC}$ & $100 \mathrm{mM} \mathrm{NaCl}, \mathrm{pH} 7.5$ & -175 & -302 \\
\hline
\end{tabular}

The temperature dependence of the transfer enthalpies origins from a negative $\Delta C p$, which is observed when hydrophobic surfaces exposed to water are reduced [54, 76]. This is the case by transferring detergent monomers from the aqueous phase into the apolar lipid phase. In most cases, the $\Delta C p$ data are more negative for $\mathrm{NaDC}$ compared to $\mathrm{NaC}$. An increase of the ionic strength makes $\Delta C p$ data more negative (Table 5).

The comparison of the $\Delta C p$ data for the partitioning of detergent monomers in a lipid phase with the $\Delta C p$ data for the partitioning of detergent monomers in a micellar phase show strong differences. For the micellisation process of $\mathrm{NaC}$ and NaDC $\Delta C p$ data ranges between -260 and $-360 \mathrm{~J} \cdot \mathrm{K}^{-1} \cdot \mathrm{mol}^{-1}$. Due to the fact that the $\Delta C p$ data are more negative for the micellisation process, it can be stated that a change in exposed apolar surface area to water is smaller by transferring bile salt monomers into membranes compared to micelles. However, it has to be considered that a partial compensation of this effect may occur, because apolar parts of the lipid molecule may be further exposed to water due to the 
incorporation of monomer molecules, and thus perturbing the lipid organisation in the bilayer membrane [76].

With increasing temperature the partition coefficient $P_{\text {av }}$ for SPC decreases slightly, however this trend depends on the fatty acid composition of the membrane. The effect on temperature on the solubilisation process shows that higher amounts of detergents are required when the temperature is raised, which is due to the fact that the coexistence region is reached at higher detergent concentrations for the solubilisation experiment. The width of the coexistence range, however, is quite similar and more or less only slightly temperature dependent. The $R_{\mathrm{e}}^{\#}$ data show a similar tendency with temperature and with salt for both lipid systems.

\section{Influence of the phospholipid chain length of PC liposomes}

The required detergent amount for membrane solubilisation is considerably lower for lipid membranes with shorter chains compared to the same lipid with longer acyl chains. This is even obvious for an acyl chain difference of just two methylene units. Comparing DMPC (C14-PC) and DPPC (C16-PC) shows that for DMPC the slopes of the phase boundaries are smaller and identical for both phase boundaries $\left(R_{\mathrm{e}}^{\#} \approx 0.065\right)$. This means the amount of detergent in the mixed vesicles and micelles is lower for phosphatidylcholines with shorter (C14) acyl chains compared to lipid analogue with longer acyl chains (C16). The reason for this behaviour lies in the fact that lipids with short hydrocarbon chains form much more easier surfaces with positive curvatures as they occur in micelles, compared to lipids with longer acyl chains [87-91].

\section{Influence of the saturation degree of the acyl chains of the membrane}

In order to get more insight with regards to the influence of the saturation degree of the acyl chains three different lipid systems with similar acyl chain lengths were investigated: DPPC (synthetic lipid, both acyl chains saturated), POPC (synthetic lipid, one acyl chain saturated, one acyl chain unsaturated) and SPC (naturally occurring lipid system with higher degree of unsaturated acyl chains in addition to higher acyl chain heterogeneity).

Comparing the SPC and POPC systems it can be stated that the phase boundaries for the solubilisation with $\mathrm{NaC}$ are found at higher detergent concentration for all phospholipids compared to the solubilisation with NaDC. This is due to the lower $\mathrm{cmc}$ of NaDC.

Decreasing the ionic strength reduces the ionic shielding effect of the polar head groups of the detergent molecules and as a consequence the phase boundaries are shifted to higher bile salt concentrations. The difference is more pronounced for POPC than for SPC.

The width of the phase boundaries depends also on the saturation degree of the acyl chains (Figure 11). For $\mathrm{NaC}$ mixtures in water the phase boundaries are narrower for POPC than for SPC. The solubilisation process requires higher bile salt concentrations for SPC compared to POPC, whereas for the saturation process similar detergent amounts are required. The phase boundaries for dihydroxy bile salt in water and both bile salts in $100 \mathrm{mM} \mathrm{NaCl}$ show similar positions for SPC and POPC. The $R_{\mathrm{e}}^{\text {sol }}$ values are larger for SPC compared to POPC, which implicates the mixed micelles are formed with larger amount of detergent molecules within the aggregate. 
Figure 11. Phase boundaries for the vesicle to micelle transition induced by $\mathrm{NaC}(100$ $\mathrm{mM} \mathrm{NaCl}, p H$ 7.5) for different lipid systems DPPC (dotted lines), POPC (dashed lines) and SPC (solid lines) at $60{ }^{\circ} \mathrm{C}$.

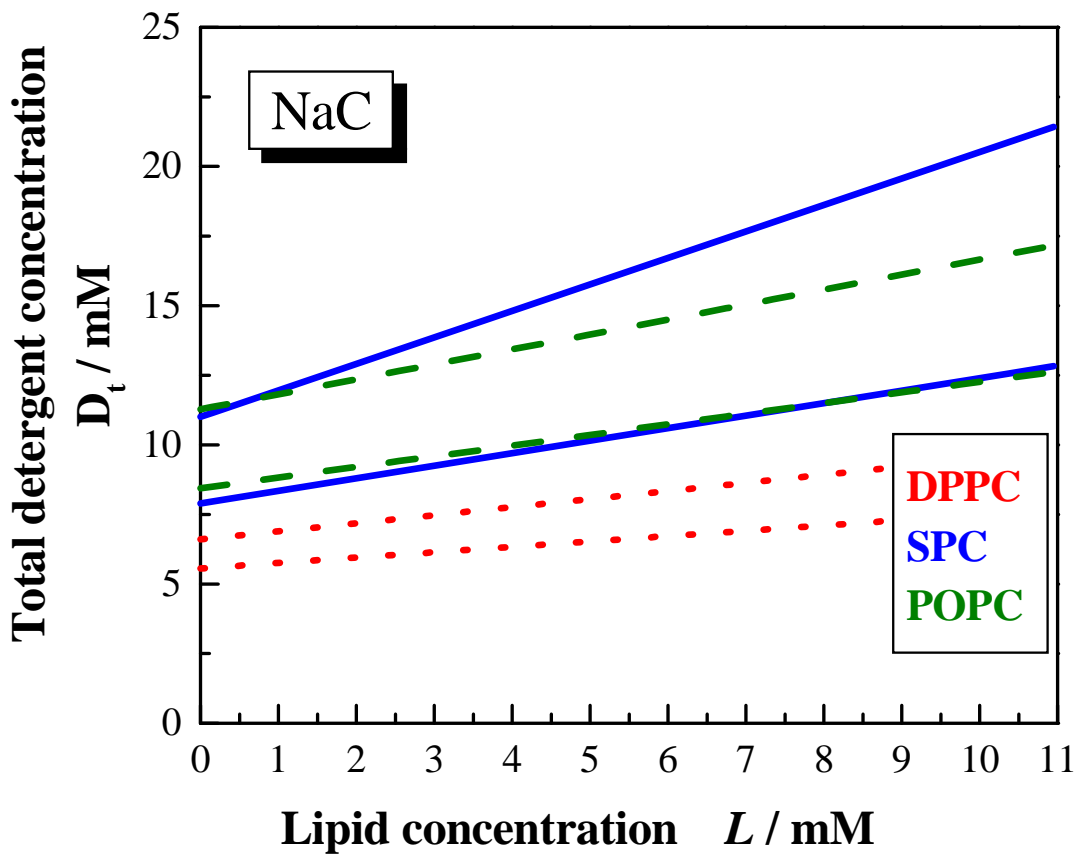

$D_{\mathrm{w}}{ }^{\#}$ values obtained for the bile salt mixtures with SPC and POPC (both in $100 \mathrm{mM} \mathrm{NaCl}$ ) are obviously below the $\mathrm{cmc}$. For detergent to lipid mixtures dispersed in water, the $D_{\mathrm{w}}{ }^{\#}$ values for the $\mathrm{NaDC}$ containing systems are in the range of the $\mathrm{cmc}$ and for the $\mathrm{NaC}$ containing systems they are higher than the $\mathbf{c m c}$. This lead to the conclusion, that the charge shielding effect of the detergent molecules in $100 \mathrm{mM} \mathrm{NaCl}$ favors the disruption of the bilayer membranes. Probably, the bile salt molecules now can form multimeric aggregates in the bilayer making them unstable. This is supported by the lower $R_{\mathrm{e}}{ }^{\text {sat }}$ values obtained for solubilisation in salt solutions.

Compared to the membranolytic resistance of membranes with unsaturated acyl chains [59], it is observed that phospholipids with saturated acyl chains [56, 92] are more easily transformed into micelles. In other words, less detergent is required for the solubilisation of saturated bilayer membranes compared to unsaturated lipid analogues. Figure 11 summarises the phase boundaries for the DPPC, SPC, and POPC solubilisation by $\mathrm{NaC}\left(60^{\circ} \mathrm{C}, 100 \mathrm{mM} \mathrm{NaCl}, \mathrm{pH} 7.5\right)$.

The detergent to lipid ratios for the saturation as well as for the solubilisation process are higher for unsaturated lipids compared to a lipid of similar chain length, however with saturated hydrocarbon chains. Furthermore, the phase boundaries are located at lower total detergent concentration. The higher susceptibility of saturated lipids for the transformation into mixed micelles is most likely due to their larger tendency for the formation of positively curved surfaces. Lipids with unsaturated acyl chains have a tendency for the formation of aggregates with negative curvature and are thus less easily transformed into aggregates with positive curvature. 
Influence of the surface charge density of the membrane

The influence of the surface charge membrane density [93] with regards to the interaction of the anionic bile salts $\mathrm{NaC}$ and $\mathrm{NaDC}$ into lipid vesicles composed of pure negatively charged DPPG or mixtures of DPPC and DPPG at molar ratios of 3:1 and 1:1 were investigated (100 mM NaCl, $p H$ 7.4) in the liquid crystalline phase. The obtained results clearly indicate that the partition process is dependent on the structure of the bile salt molecules; higher partition coefficient for NaDC are obtained due to its higher hydrophobicity [62].

The results illustrate that the transfer enthalpies for partitioning of the bile salts in purely zwitterionic vesicles (DPPC) and purely negatively charged vesicles (DPPG) are almost the same, however different for the two bile salts $\left(\Delta H^{\mathrm{T}}\left(\mathrm{NaC}, 100 \mathrm{mM} \mathrm{NaCl}, p H 7.4, T=60{ }^{\circ} \mathrm{C}\right) \approx-4.2 \mathrm{~kJ} \cdot \mathrm{mol}^{-1}\right.$ and $\left.\Delta H^{\mathrm{T}}\left(\mathrm{NaDC}, 100 \mathrm{mM} \mathrm{NaCl}, p H 7.4, T=60^{\circ} \mathrm{C}\right) \approx-11.4 \mathrm{~kJ} \cdot \mathrm{mol}^{-1}\right)$. The partition coefficients are also very similar for the two lipid system, but different for the bile salts $\left(P_{\mathrm{av}}(\mathrm{NaC}, 100 \mathrm{mM} \mathrm{NaCl}, p H\right.$ $\left.7.4, T=60^{\circ} \mathrm{C}\right) \approx 4 \cdot 10^{4}$ and $P_{\text {av }}\left(\mathrm{NaDC}, 100 \mathrm{mM} \mathrm{NaCl}, p H 7.4, T=60^{\circ} \mathrm{C}\right) \approx 2 \cdot 10^{5}$ ). Astonishingly, the surface charge density of the negatively charged lipid systems plays only a minor role [62].

The constructed vesicle-to-micelle phase diagrams, based on ITC, reflect differences in the saturation and solubilisation processes between $\mathrm{NaC}$ and $\mathrm{NaDC}$, as described before. The parameters of the phase transition in bile salt/phospholipid mixtures show a strong solubilising efficacy of bile salts in contrast to classical head-tail-detergents [20,41]. Low amounts of bile salts are required for the formation of mixed micelles. This is in agreement with DLS results.

From the solubilisation data of liposomes bearing different surface charge densities, no apparent charge effects on the vesicle-to-micelle transition could be found. The results can be understand when the curvature tendency of the mixed systems is considered. The found properties show that there is an influence of the detergent partitioning related to the spontaneous curvature of the vesicles. DPPG vesicles require lower bile salt concentrations for the solubilisation compared to DPPC vesicles, which is explained by the higher spontaneous curvature tendency of PG-liposomes. For the mixed DPPC/DPPG vesicles higher bile salt concentrations are necessary for the solubilisation than for the pure phospholipid vesicles caused by the differentiated vesicle-to-micelle transition due to the asymmetric distribution of DPPC and DPPG in the inner and outer vesicle layer. This behaviour is more pronounced for the 3:1 mixture with the higher amount of DPPC (75 w\%) compared to the 1:1 mixture with only 50 w\% DPPC.

\section{Influence of the phase properties}

The results presented above were all obtained with biological model membranes in the liquid crystalline phase. Under these conditions the membranes become permeable at low detergent concentrations. However, studies of the vesicle-to-micelle transition in the gel phase are not feasible using ITC or DLS, because the kinetics of detergent incorporation in the membrane is too slow. This is due to the slow flip-flop process of gel membranes [71]. However, using another calorimetric technique, DSC, it is possible to investigate the detergent-membrane interaction [56, 94]. Thus, it is possible to analyse it if gel phase membranes are converted to mixed micelles at similar detergent 
saturation concentrations as found for liquid crystalline phase membranes. Furthermore, one might get insights in the distribution of detergent molecules in liquid crystalline versus gel phase domains.

The presence of small concentrations of detergent abolish the pretransition $\left(\mathrm{L}_{\beta}, \rightarrow \mathrm{P}_{\beta}\right.$ ) of PC membranes [54]. The main phase transition temperature $\left(\mathrm{P}_{\beta}, \rightarrow \mathrm{L}_{\alpha}\right)$ is shifted to lower temperature indicating a destabilisation of the gel phase. Increasing the amount of detergent induces the apparition of two peaks in the DSC curves. The first peak, located at lower temperature, is in general much sharper, compared to the broader second peak found at higher temperature. However, both peaks occur at lower temperature compare to the temperature of the main phase transition of the pure PC [56].

The occurrence of the two peaks is due to the formation of gel phase and liquid crystalline phase domains which coexist over a larger temperature range. This corresponds to the results presented by Forte et al. [98] for taurocholate/DPPC systems.

An increase of the detergent concentration induces a broadening of the phase transition and a strong decrease of the phase transition enthalpy. The complete disappearance of the phase transition occurs at much higher detergent concentrations as necessary for the solubilisation of liquid crystalline membranes. These results reflect that less detergent is incorporated in gel phase membranes, and heating the system (as in done in the DSC experiment) induce a transformation of gel phase mixed vesicles coexisting with mixed micelles into pure mixed micelles [56].

\section{Conclusions}

The presented study reflects the potential of isothermal titration calorimetry for the investigation of the membranolytic properties of detergent. The two main membranolytic processes, i.e. detergent distribution in the membrane and solubilisation of the membrane are analysed in detail.

Less $\mathrm{NaDC}$ is required for the solubilisation of membranes compared to NaC. Thus NaDC has a higher membranolytic activity. The partition of $\mathrm{NaC}$ in phospholipid membranes follows a one single partition mechanism, whereas the data for NaDC suggest a more complicated interaction via a twostep partition process. The phase boundaries for the solubilisation with $\mathrm{NaC}$ are at higher detergent concentration for all phospholipids compared to the solubilisation process with NaDC. Increasing the ionic strength induce a better shielding of the polar headgroups of the detergent molecules and as a consequence a shift of the phase boundaries to lower detergent concentrations. The environmental solution properties such as the ionic strength or temperature have a strong influence on the solubilisation strength of the detergents.

Negative changes in heat capacity are observed when hydrophobic surfaces self-associate and form larger aggregates, with the apolar part of the molecule shielded from the polar water phase. The presented results clearly show that the apolar part of the bile salt molecules are more effectively protected from the aqueous phase when the detergent molecules self-aggregate and form micelles compared to the lower apolar shielding in mixed vesicles.

With regards to the effect of membrane surface charge, it is found that electrostatic repulsion between negatively charged membranes and negatively charges bile salt molecules are of minor importance and not a limiting factor for the vesicle-to-micelle transition. More of relevance are the lipid geometry and thus membrane packing constrains of the lipid molecule and the related tendency for the spontaneous formation of curved structures. 
Comparing bile salt detergents with other detergents, show that bile salts have a much higher membranolytic and solubilisation potential. Biological model membranes with saturated lipids are more unstable than those of unsaturated lipids. This is based on the larger tendency of saturated lipids for the formation of surfaces with positive curvatures.

\section{Experimental}

\section{Materials}

The phospholipids 1,2-dimyristoyl-sn-glycero-3-phosphatidylcholine (DMPC), 1,2-dipalmitoyl-snglycero-3-phosphatidylcholine (DPPC) and 1,2-dipalmitoyl-sn-glycero-3-phosphatidyl-glycerol (DPPG) were obtained from Genzyme Pharmaceuticals and Sygena Facility (Liestal, Switzerland), soybean phosphatidylcholine (SPC) was kindly provided by Nattermann Phospholipid GmbH (Cologne, Germany), 1-palmitoyl-2-oleoyl-sn-glycero-3-phosphatidylcholine (POPC) was a gift from Lipoid GmbH (Ludwigshafen, Germany). The phospholipids were pure as checked by thin-layer chromatography [64]. The bile salts sodium cholate $(\mathrm{NaC})$ and sodium deoxycholate (NaDC) were purchased from Sigma (Deisenhofen, Germany). The purity of the bile salts was tested by mass spectrometry (Finnigan LCQ; Thermoquest, San Jose, CA, USA). Sodium chloride of p.a. grade was purchased from Merck (Darmstadt, Germany). All water used was ultra pure as obtained from a Milli-Q system (Millipore; Molsheim, France).

\section{Sample preparations}

The bile salt solutions were prepared by dissolving a certain amount in pure water or $0.1 \mathrm{M} \mathrm{NaCl}$. The pure phospholipid dispersions were prepared by suspending definite amounts of lipid in pure water or $0.1 \mathrm{M} \mathrm{NaCl}$. The binary lipid mixtures at various molar ratios were prepared by dissolving the appropriate amount of lipid in chloroform/methanol (2:1 v/v), and the binary lipid film was obtained by a rapid removal of the organic solvent by incubation in a water bath under nitrogen atmosphere (Pierce Reacti-Therm ${ }^{\mathrm{TM}}$ Heating/Stirring Module, Pierce Chemical Company, Rockford, IL, USA). The samples were stored over night in a cabinet drier (Heraeus Instruments, Kendro Laboratory Products GmbH, Hanau, Germany) to remove residual traces of organic solvent. The mixed phospholipid films were then prepared by adding the aqueous solution and vortexing (VF 2, IKALaborgeraete Janke \& Kunkel, IKA-Werke GmbH, Staufen, Germany) the crude dispersions for 5 min at a temperature above the respective main phase transition temperature $T_{\mathrm{m}}$ of the lipid, followed by mild ultrasonication (Elma Transsonic 310/H, Elma - Hans Schmidbauer GmbH, Singen, Germany) in a water bath at $60{ }^{\circ} \mathrm{C}$ for a time period between 5 and $20 \mathrm{~min}$., depending on the lipid concentration (for more details see [54, 62]). The liposome size was determined by dynamic light scattering (DLS) using a ALV-NIBS-HPPS DLS instrument (ALV-Laser Vertriebsgesellschaft mbH, Langen, Germany). The solutions were degassed (Thermolyne ${ }^{\circledR}$ Nuova ${ }^{\mathrm{TM}}$ Magnetic Stirrer, Barnstead /Thermolyne, Dubuque, IA, USA) and the $p H$ of all samples was adjusted to 7.4 (Microprocessor pH/Ion Meter pMX 3000, WTW GmbH, Weilheim, Germany). All samples were freshly prepared before the experiments. 
Isothermal titration calorimetry (ITC)

The isothermal titration experiments were done with a MicroCal OMEGA titration calorimeter and an MCS ITC unit (MicroCal, Inc., Northhampton, MA, USA) as described before [62, 65, 79]. The calorimeter sample cell volume is $V=1.368 \mathrm{~mL}$. The reference cell was filled with pure water or $0.1 \mathrm{M} \mathrm{NaCl}$ solution. The lipid and detergent concentrations were chosen in such a way that the processes of partitioning and solubilisation occurred during the experiments. The lipid to detergent interactions were studied in the liquid crystalline phase, i.e. at a temperature above the main phase transition of the lipids under investigation [54, 64]. The experimental data were analysed using the ORIGIN ${ }^{\mathrm{TM}}$ software for ITC as provided by MicroCal.

\section{Partition experiments by means of ITC}

For a partition experiment the sample cell was filled with a detergent solution with low concentration $\left(c_{\text {detergent }}<<c m c, c m c=\right.$ critical micelle concentration) and the titration syringe $(250 \mu \mathrm{L})$ was loaded outside the calorimeter with a highly concentrated phospholipid dispersion. The phospholipid dispersion is then titrated in defined aliquots into the sample cell containing the bile salt solution and the heat flow is registered (Figure 2). During the titration experiment the syringe rotated at $\approx 400 \mathrm{rpm}$. Briefly, the experimental details for the system PC/PG were as follow (for more detail see [96]): the phospholipid dispersions at a concentration of $20 \mathrm{mM}$ were titrated with $50 \times 5 \mu \mathrm{L}$ injections for DPPC and with $25 \times 10 \mu \mathrm{L}$ ones for DPPG and the DPPC/DPPG mixtures into a $4 \mathrm{mM}$ $\mathrm{NaC}$ or a $1 \mathrm{mM} \mathrm{NaDC}$ solution in $0.1 \mathrm{M} \mathrm{NaCl}$. The corresponding details are summarised in the figure legends. Three to five individual measurements were performed for each system to check for reproducibility. The heats of dilution were obtained by titrating the lipid dispersion into $0.1 \mathrm{M} \mathrm{NaCl}$ solution and subtracted from the molar titration heats. The non-linear least square fits of the experimental data were performed using the SCIENTIST for windows ${ }^{\mathrm{TM}}$ software (MicroMath Scientific Software, Inc., Salt Lake City, UT, USA) as described before [59, 62].

\section{Solubilisation experiments by means of ITC}

Solubilisation experiments were prepared by filling the sample cell with a phospholipid dispersion and the titration syringe $(250 \mu \mathrm{L})$ was loaded with a detergent solution $\left(c_{\text {detergent }}>>c m c\right)$. During the titration experiment the syringe rotated at $\approx 400 \mathrm{rpm}$, the volume of the syringe was injected into the cell in aliquots between 5 and $20 \mu \mathrm{L}$. Membrane solubilisation was investigated for phospholipid dispersion of a defined concentration between 0.5 and $10 \mathrm{mM}$. A bile salt solution with a high concentration well above the $c m c$ was added with $40 \times 6.25 \mu \mathrm{L}$ injections. The solubilisation of e.g. DPPC, DPPG and DPPC/DPPG mixtures with both bile salts, $\mathrm{NaC}$ and NaDC, was investigated in $\mathrm{H}_{2} \mathrm{O}$ and $0.1 \mathrm{M} \mathrm{NaCl}$ at $p H$ 7.5. The concentration of the $\mathrm{NaC}$ solution was $100 \mathrm{mM}$, the $\mathrm{NaDC}$ solution was titrated into the calorimeter cell at a concentration of $50 \mathrm{mM}$. To test the reproducibility three to five individual experiments were carried out [59,62]. The corresponding experimental details are summarised in the figure legends. 


\section{Differential scanning calorimetry (DSC)}

Differential scanning calorimetry (DSC) measurements were performed with a VP-DSC scanning calorimeter (MicroCal, Inc., Northampton, MA, USA). For the DSC experiments the corresponding lipid dispersion were filled in the sample cell and the reference cell was filled with the pure aqueous solution. The used lipid concentrations ranged between 3 and $6 \mathrm{mM}$. The calorimeter sample cell volume was $V=0.5 \mathrm{~mL}$. The heating and cooling rate was $1 \mathrm{~K} \cdot \mathrm{min}^{-1}$. Heating curves were measured in the temperature interval from 5 to $95{ }^{\circ} \mathrm{C}$. The base line was obtained by measuring a water or $0.1 \mathrm{M} \mathrm{NaCl}$ solution in the sample cell and subtracted from the lipid/detergent heating curves. The experimental data were analysed using the ORIGIN ${ }^{\mathrm{TM}}$ software for DSC as provided by MicroCal.

\section{Dynamic light scattering (DLS)}

The DLS experiments were performed with a ALV-NIBS HPPS particle sizer (ALV-Laser Vertriebsgesellschaft $\mathrm{mbH}$, Langen, Germany). The device was equipped with a $3 \mathrm{~mW}$ HeNe-laser with a wavelength of $632.8 \mathrm{~nm}$. Due to the principle of non-invasive back scattering the scattering angle was $173^{\circ}$. Dynamic light scattering was used for studying solubilisation properties of lipid dispersions in water ( $p H 7.4$ ) or $0.1 \mathrm{M} \mathrm{NaCl}(p H 7.4)$ by the two bile salts $\mathrm{NaC}$ and NaDC. The measurements were carried out at similar temperatures as performed for the ITC solubilisation experiments (see text). The quartz cuvette (HELLMA GmbH \& Co. KG, Muellheim, Germany) contained the phospholipid dispersion of a defined concentration (1, 3, and $6 \mathrm{mM})$. A bile salt solution with a high concentration well above the $c m c(100 \mathrm{mM}$ for $\mathrm{NaC}$ and $50 \mathrm{mM}$ for $\mathrm{NaDC})$ was added from the application pipette (Multipette ${ }^{\circledR}$ with a $0.1 \mathrm{~mL}$ application unit) in $20 \mu \mathrm{L}$ steps into the sample holder. All samples were freshly prepared and then filtered through a membrane filter of $0.45 \mu \mathrm{m}$ pore size for the phospholipid dispersions and $0.2 \mu \mathrm{m}$ pore size for the bile salt solutions into the dust-cleaned cuvettes. Three individual measurements were performed for each system to test the reproducibility. The experimental data were analysed using the ALV-5000/E software based on the modified CONTIN method [97] taking the temperature correction of the viscosity into account.

\section{Small angle neutron scattering (SANS)}

The lipid dispersions were prepared as described above, however for the SANS experiments in $\mathrm{D}_{2} \mathrm{O}$ instead of $\mathrm{H}_{2} \mathrm{O}$ [82]. Various dispersions at various lipid-to-detergent ratios were prepared in advance. The samples were incubated for $5 \mathrm{~h}$ at temperatures above the main phase transitions of the lipid (e.g. for the DPPC-bile acid systems at $60{ }^{\circ} \mathrm{C}$ ) and filtered through a $0.2 \mu$ mylon-filter in the quartz cuvette (Hellma GmbH \& Co. KG, Müllheim). The SANS experiments were performed at the Hahn-Meitner-Institute (BENS: Berliner Neutronenstreuzentrum), Berlin (Germany) [95]. The measurements were obtained using a V4-small angle scattering unit. In order to compare the results with the ITC results, the same temperature ranges were investigated [64]. The data were evaluated as described previously [84]. 


\section{Acknowledgements}

Bettina Fölting is thanked for her excellent technical assistance and Dr. Martin Janich (MLU, Department of Physics) for the SANS experiments.

\section{References and Notes}

1. Berzelius, J. Über die Zusammensetzung der Galle. Arch. Pharm. 1840, 74, 275-289.

2. Freiherrn von Gorup-Besanez, E. Untersuchungen über Galle. Ann. Chem. Pharm. 1846, 59, 129159.

3. Menzies, J. A. Observation on the secretion and composition of human bile. Biochem. J. 1912, 6, 210-218.

4. Vlahcevic, Z. R.; Schwartz, C. C.; Gustafsson, J.; Halloran, L. G.; Danielsson, H.; Swell, L. Biosynthesis of bile acids in man. J. Biol. Chem. 1980, 255, 2925-2933.

5. Mukhopadhyay, S.; Maitra, U. Chemistry and biology of bile acids. Curr. Sci. 2004, 87, 16661683.

6. Enhsen, A.; Kramer, W.; Wess, G. Bile acids in drug discovery. DDT 1998, 3, 409-418.

7. Hofmann, A. F. The enterohepatic circulation of bile acids in man. Adv. Int. Med. 1976, 21, 501534.

8. Hofmann, A. F. Bile acids: the good, the bad, and the ugly. News Physiol. Sci. 1999, 14, 24-29.

9. St-Pierre, M. V.; Kullak-Ublick, G. A.; Hagenbuch, B.; Meier, P. J. Transport of bile acids in hepatic and non-hepatic tissues. J. Exp. Biol. 2001, 204, 1673-1686.

10. Tam, J. P.; Wu, C.; Yang, J. L. Membranolytic selectivity of cystine-stabilised cyclic protegrins. Eur. J. Biochem. 2000, 267, 3289-3300.

11. Asamoto, Y.; Tazuma, S.; Ochi, H.; Chayama, K.; Suzuki, H. Bile-salt hydrophobicity is a key factor regulating rat liver plasma membrane communication: relation to bilayer structure, fluidity and transporter expression and function. Biochem. J. 2001, 359, 605-610.

12. Hamada, T.; Goto, H.; Yamahira, T.; Sugawara, T.; Imaizumi, K.; Ikeda, I. Solubility in and affinity for the bile salt micelle of plant sterols are important determinants of their intestinal absorption in rats. Lipids 2006, 41, 551-556.

13. van Minnen, L. P.; Venneman, N. G.; van Dijk, J. E.; Verheen, A.; Gooszen, H. G.; Akkermans, L. M. A.; Erpecum, K. J. Cholesterol crystals enhance and phospholipids protect against pancreatic induced by hydrophobic bile salts: a rat model study. Pancreas 2006, 32, 369-375.

14. Cai, X.; Grant, D. J. W. ; Wiedmann, T. S. Analysis of the solubilisation of steroids by bile salt micelles. J. Pharmaceut. Sci. 1997, 86, 372-377.

15. Szydlowska, H.; Zaporowska, E.; Kuszlik-Jochym, K. Membranolytic activity of detergents as studied with cell viability tests. Folia Histochem. Cytochem. (Krakow) 1978, 16, 69-78.

16. Ross, B. P.; Braddy, A. C.; McGeary, R. P.; Blanchfield, J. T.; Proklai, L.; Toth, I. Micellar aggregation and membrane partitioning of bile salts, fatty acids, sodium dodecyl sulfate, and sugar-conjugated fatty acids: correlation with hemolytic potency and implications for drug delivery. Mol. Pharmaceut. 2004, 1, 233-245.

17. Hofmann, A. F. Detoxification of lithocholic acid, a toxic bile acid: relevance to drug hepatotoxicity. Drug Metabol. Rev. 2004, 36, 703-722. 
18. Solaas, K.; Ulvestad, A.; Söreide, O.; Kase, B. F. Subcellular organisation of bile acid amidation in human liver: a key issue regulating the biosynthesis of bile salts. J. Lipid Res. 2000, 41, 11541162.

19. Majhi, P. R.; Blume, A. Temperature-induced micelle-vesicle transitions in DMPC-SDS and DMPC-DTAB mixtures studied by calorimetry and dynamic light scattering. J. Phys. Chem. B 2002, 106, 10753-10763.

20. Heerklotz, H. The microcalorimetry of lipid membranes. J. Phys.: Condens. Mat. 2004, 16, R441R467.

21. Lasch, J. Interaction of detergents with lipid vesicles. Biochim. Biophys. Acta 1995, 1241, 269292.

22. Tanford, C., The Hydrophobic Effect: Formation of Micelles and Biological Membranes, $2^{\text {nd }}$ edn.; Wiley: New York, 1980.

23. Moroi, Y. Micelles. Theoretical and Applied Aspects; Springer-Verlag: Berlin, 1992.

24. Garidel, P.; Hildebrand A. Thermodynamic properties of association colloids. J. Therm. Anal. Calorim. 2005, 85, 483-489.

25. Keller, M. Thermodynamik der Demizellisierung und Solubilisierung von Alkylglucosiden mit ausgewählten Phospholipiden sowie das rheologische Verhalten der Solubilisierung am Beispiel Octylglucosid/Dimyristoylphosphatidylglyzerol. Ph.D. thesis, Universität Kaiserslautern, Germany, 2001.

26. Lasch, J.; Schubert, R. The interaction of detergents with liposomal membranes. In Liposome Technology, $2^{\text {nd }}$ edition; Gregoriadis, G. (ed.), CRC Press: Boca Raton, 1993; Volume II, Chapter 14, pp. 233-260.

27. Keller, S.; Heerklotz, H.; Jahnke, N.; Blume, A. Thermodynamics of lipid membrane solubilisation by dodecyl sulfate. Biophys. J. 2006, 90, 4509-4521.

28. Keller, M.; Kerth, A.; Blume, A. Thermodynamics of interaction of octyl glucoside with phosphatidylcholine vesicles: partitioning and solubilisation as studied by high sensitivity titration calorimetry. Biochim. Biophys. Acta 1997, 1326, 178-192.

29. Garidel, P.; Hildebrand, A.; Blume A. Understanding the self-organisation of association colloids, MicroCal application note, 2004; pp. 1-12.

30. Simonovic, B. R.; Momirovic, M. Determination of critical micelle concentration of bile acid salts by micro calorimetric titartion. Microchim. Acta 1997, 127, 101-104.

31. Mazer, N. A.; Quasielasctic light scattering studies of aqueous biliary lipid systems and native bile. Hepatology 1990, 12, 39S-44S.

32. Small, D. M. Size and structure of bile salt micelles: influence of structure, concentration, counterion concentration, $\mathrm{pH}$, and temperature. Adv. Chem. Ser. B 1968, 84, 31-52.

33. Small, D. M.; Penkett, S. A.; Chapman, D. Studies on simple and mixed bile salt micelles by nuclear magnetic resonance spectroscopy. Biochim. Biophys. Acta 1969, 176, 178-189.

34. Kawamura, H.; Murata, Y.; Yamaguchi, T.; Igimi, H., Tanaka, M.; Sugihara, G.; Kratovihil, J. P. Spin label studies of bile salt micelles. J. Phys. Chem. 1989, 93, 3321-3326.

35. Coello, A.; Meijide, F.; Rodriguez-Nunez, E.; Tato, J. V. Aggregation behaviour of bile salts in aqueous solution. J. Pharm. Sci. 1996, 85, 9-15. 
36. Galantini, L.; Giglio, E.; Pavel, N. V.; Punzo, F. QELS and X-ray of two dihydroxy bile salt aqueous solutions, Colloid. Surface. A 2004, 248, 79-84.

37. Warren, D. B.; Chalmers, D. K.; Hutchinson , K.; Dang, W.; Poton, C. W. Molecular dynamics simulation of spontaneous bile salt aggregation. Colloid. Surface. A 2006, 280, 182-193.

38. Michael, S.; Thöle, M.; Dillmann, R.; Fahr, A.; Drewe, J.; Frickert, G. Improvement of intestinal peptide absorption by synthetic bile acid derivative, cholylsarcosine. Eur. J. Pharm. Sci. 2000, 10, 133-140.

39. Wiedmann, T. S.; Kamel, L. Examination of the solubilisation of drugs by bile salt micelles. $J$. Pharmaceut. Sci. 2002, 91, 1743-1764.

40. Wiedmann, T. S.; Liang, W.; Kamel, L. Solubilisation of drugs by physiological mixtures of bile salts. Pharm. Res. 2002, 19, 1203-1208.

41. Garidel, P.; Lasch. J. Mixed vesicles and mixed micelles: formation, thermodynamic stability, and pharmaceutical aspects. In Liposome Technology. Volume I. Liposome Preparation and Related Techniques; Gregoriadis, G. (ed.); Informa Healthcare: New York, 2007; Chapter 11, pp. 209240.

42. Simões, S. I., Marques, C. M.; Cruz, M. E. M.; Cev, G.; Martins, M. B. F. The effect of cholate on solubilisation and permeability of simple and protein-loaded phosphatidylcholine/sodium cholate aggregates designed to mediate transdermal delivery of macromolecules. Eur. J. Pharm. Biopharm. 2004, 58, 509-519.

43. Cevc, G. Lipid vesicles and other colloids as drug carriers on the skin. Adv. Drug. Del. Rev. 2004, 56, 675-711.

44. Tamminen, J.; Kolehmainen, E. Bile acids as building blocks of supramolecular hosts. Molecules 2001, 6, 21-46.

45. Koivukorpi, J.; Sievänen, E.; Kolehmainen, E.; Král, V. Synthesis, characterization, and saccharide binding studies of bile acid - porphyrin conjugates. Molecules 2007, 12, 13-24.

46. Davis, A. P.; Wareham, R. S. Carbohydrate recognition through noncovalent interactions: a challenge for biomimetic and supramolecular chemistry. Angew. Chem. Int. Ed. Engl. 1999, 38, 2978-2996.

47. Virtanen, E.; Kolehmainen, E. Use of bile acids in pharmacological and supramolecular applications. Eur. J. Org. Chem. 2004, 3385-3399.

48. Schubert R., Gallensäure-Membran-Wechselwirkung. Proc. MoBBEL 1987, 2, 29-40.

49. Keller, S.; Tsamaloukas, A.; Heerklotz, H. A quantitative model describing the selective solubilisation of membrane domains. J. Am. Chem. Soc. 2005, 127, 11469-11476.

50. Lichtenberg, D. Characterisation of the solubilisation of lipid bilayers by surfactants. Biochim. Biophys. Acta 1985, 821, 470-478.

51. Hoffmann La Roche AG, Valium MM: Fachinformation 1999.

52. Béven, L.; Castano, S.; Dufourcq, J.; Wieslander, A.; Wróblewski, H. The antibiotic activity of cationic linear amphipathic peptides: lessons from the action of leucine/lysine copolymers on bacteria of the class Mollicutes. Eur. J. Biochem. 2003, 270, 2207-2217.

53. Andrä, J.; Gutsmann, T.; Garidel, P. Brandenburg, K. Mechanisms of endotoxin neutralisation by synthetic cationic compounds. J. Endotox. Res. 2006, 12, 261-277. 
54. Blume, A., Garidel, P., Lipid model membranes and biomembranes. In: Gallagher, P. K. (series ed.), The Handbook of Thermal Analysis and Calorimetry, Kemp, R. B. (ed.), From Macromolecules to Man, $1^{\text {st }}$ ed.; Elsevier: Amsterdam, 1999; Vol. 4, pp. 109-173.

55. Heerklotz, H. H.; Lantsch, G.; Binder, H.; Klose, G.; Blume, A. Application of isothermal titration calorimetry for detecting lipid membrane solubilisation. Chem. Phys. Lett. 1995, 235, 517-520.

56. Hildebrand, A.; Neubert, R.; Garidel, P.; Blume, A. Bile salt induced solubilization of synthetic phosphatidylcholine vesicles studied by isothermal titration calorimetry. Langmuir 2002, 18, 2836-2847.

57. Heerklotz, H.; Seelig, J. Titration calorimetry of surfactant-membrane partitioning and membrane solubilisation. Biochim. Biophys. Acta 2000, 1508, 69-85.

58. Keller, S.; Böthe, M.; Bienert, M.; Dathe, M.; Blume, A. A simple fluoresence-spectroscopic membrane translocation assay. ChemBioChem 2007, 8, 546-552.

59. Hildebrand, A.; Beyer, K.; Neubert, R.; Garidel, P.; Blume, A. Temperature dependence of the interaction of cholate and deoxycholate with fluid model membranes and their solubilisation into mixed micelles. Colloids Surf. B. 2003, 32, 335-351.

60. Kuchinka, E.; Seelig, J. Interaction of melittin with phosphatidylcholine membranes. Binding isotherm and lipid head-group conformation. Biochemistry 1989, 28, 4216-4221.

61. Möhwald, H. Phospholipid monolayers. In Structures and Dynamics of Membranes. From Cells to Vesicles; Lipowsky, R., Sackmann, E. (Eds.); Elsevier: Amsterdam, 1995; Vol. 1A. pp. 161212.

62. Hildebrand, A.; Beyer, K.; Neubert, R.; Garidel, P.; Blume, A. Solubilization of negatively charged DPPC/DPPG liposomes by bile salts. J. Colloid Interf. Sci. 2004, 279, 559-571.

63. Israelachvili, J. N. Intermolecular and surface forces; Academic Press: New York, 1992.

64. Hildebrand, A. Physikochemische Charakterisierung von Gallensalz-Mischmizellen als Grundlage für innovative Arzneistoffträgersysteme. $\mathrm{PhD}$ thesis, Martin-Luther-Universität Halle/Wittenberg, Halle/Saale, 2002.

65. Hildebrand, A.; Garidel, P.; Neubert, R.; Blume, A. Thermodynamics of demicellisation of mixed micelles composed of sodium oleate and bile salts. Langmuir 2004, 20, 320-328.

66. Almgren, M. Mixed micelles and other structures in the solubilisation of bilayer lipid membranes by surfactants. Biochim. Biophys. Acta 2000, 1508, 146-163.

67. Almgren, M. Vesicle transformations resulting from curvature tuning in systems with micellar, lamellar, and bicontinuous cubic phases. J. Disp. Sci. Tech. 2007, 28, 43-54.

68. Long, M.A.; Kaler, E.W.; Lee, S. P. Structural characterisation of the micelle-vesicle transition in lecithine-bile salt solutions. Biophys. J. 1994, 67, 1733-1742.

69. Hjelm, R. P.; Alkan, H.; Thiyagaragan, P. Small-angle neutron scattering studies of mixed bile salt lecithin colloids. Mol. Cryst. Liq. Cryst. 1990, 180, 155-164.

70. Couillet, I.; Hughes, T.; Maitland, G.; Candau, F.; Candau, S. J. Growth and scission energy of wormlike micelles formed by a cationic surfactant with long unsaturated tails. Langmuir 2004, 20, 9541-9550.

71. Cabral, D. J.; Small, D. M.; Lilly, H. S.; Hamilton, J. A. Transbilayer movement of bile acids in model membranes. Biochemistry 1987, 26, 1801-1804. 
72. Lichtenberg, D.; Opatowski, E.; Kozlov, M. M. Phase boundaries in mixtures of membraneforming amphiphiles and micelle-forming amphiphiles. Biochim. Biophys. Acta 2000, 1508, 1-19.

73. Opatowski, E.; Kozlov, M. M.; Pinchuk, I.; Lichtenberg, D. Heat evolution of micelle formation, dependence of enthalpy, and heat capacity on the surfactant chain length and head group. $J$. Colloid Interf. Sci. 2002, 246, 380-386.

74. Fattal, D. R.; Andelman, D.; Ben-Saul, A. The vesicle-micelle transition in mixed lipid-surfactant systems: a molecular model. Langmuir 1995, 11, 1154-1161.

75. Roth, Y.; Opatowski, E.; Lichtenberg, D.; Kozlov, M. M. Phase behaviour of dilute aqueous solutions of lipid-surfactant mixtures: effects of finite size of micelles. Langmuir 2000, 16, 20522061.

76. Garidel, P.; Blume, A. 1,2-Dimyristoyl-sn-glycero-3-phosphoglycerol (DMPG) monolayers: influence of temperature, $\mathrm{pH}$, ionic strength and binding of alkaline earth cations. Chem. Phys. Lipids 2005, 138, 50-59.

77. Haase, R. Thermodynamik der Mischphasen; Springer Verlag: Berlin, 1956.

78. Gibbs, J. W. On the equilibrium of heterogeneous substances. In: The scientific papers of $J$. Willard Gibbs; Dover Publications: New York, 1878; Vol. 1.

79. Garidel, P.; Hildebrand, A.; Neubert, R.; Blume, A. Thermodynamic characterisation of bile salt aggregation as a function of temperature and ionic strength using isothermal titration calorimetry. Langmuir 2000, 16, 5267-5275.

80. Gouin, S.; Zhu, X.X. Fluoresence and NMR studies of the effect of a bile acid dimer on the micellisation of bile salts. Langmuir 1998, 14, 4025-4029.

81. Ollivon, M.; Lesieur, S.; Grabielle-Mandelmont, C.; Paternoster, M. Vesicle reconstitution from lipid-detergent mixed micelles, Biochim. Biophys. Acta 2000, 1508, 34-50.

82. Fitter, J.; Gutberlet, T.; Katsaras, J. (eds). Neutron scattering in biology; Springer: New York, 2006.

83. Balgavy, P.; Dubnickova, M.; Uhrikova, D.; Yaradaikin, S.; Kiselev, M.; Gordeliy, V. Bilayer thickness in unilamellar extruded egg yolk phosphatidylcholine liposomes: a small-angle neutron scattering study, Acta Phys. Slovaca 1998, 48, 509-533.

84. Janich, M.; Lange, J.; Graener, H.; Neubert, R. Extended light scattering investigations on dihydroxy bile salt micelles in low-salt aqueous solutions. J. Phys. Chem. B 1998, 102, 59575962.

85. Gordeliy, V.; Golubchikova, L. V.; Kuklin, A.; Syrykh, A. G.; Watts, A. The study of single biological and model membranes via small-angle neutron scattering. Progr. Colloid Polym. Sci. 1993, 93, 252-256.

86. Pedersen, J. S.; Egelhaaf, S. U.; Schurtenberger, P. Formationof polymerlike mixed micelles and vesicles in lecithin bile salt solutions: a small-angle neutron scattering study. J. Phys. Chem. 1995, 99, 1299-1305.

87. Fogden, A.; Hyde, S. T.; Lundberg, G. Bending energy of surfactant films. J. Chem Soc. Faraday Trans. 1991, 87, 949-955.

88. Siegel, D. P.; Kozlov, M. M. The Gaussian curvature elastic modulus of N-monomethylated dioleylphosphatidylethanolamine: relevance to membrane fusion and lipid phase behaviour. Biophys. J. 2004, 87, 366-374. 
89. Kooijman, E. E.; Chupin, V.; Fuller, N. L.; Kozlov, M. M.; de Kruijff, B.; Burger, K. N. J.; Rand, P. R. Spontaneous curvature of phosphatidic acid and lysophosphatidic acid. Biochemistry 2005, 44, 2097-2102.

90. Sackmann, E. Membrane bending energy concept of vesicle- and cell-shapes and shapetransitions. FEBS Letters 1994, 346, 3-16.

91. Siriwatwechakul, W.; LaFleur, T.; Prud'homme, R. K.; Sullivan, P. Effects of organic solvents on the scission energy of rodlike micelles. Langmuir 2004, 20, 8970-8974.

92. Subuddhi, U.; Mishra, A.K. Effect of sodium deoxycholate and sodium cholate on DPPC vesicles: a fluorescence anisotropy study with diphenylhexatriene. J. Chem. Sci. 2007, 119, 169-174.

93. Knauf, K. Physikochemische Charakterisierung homologer kationischer Tenside und deren Wechselwirkung mit Modellmembranen bestehend aus DMPC und DMPG. PhD thesis, MartinLuther-Universität Halle/Wittenberg, 2007.

94. Majhi, R. R.; Blume, A. Thermodynamic characterisation of temperature-induced micellisation and demicellisation of detergents studied by differential scanning calorimetry. Langmuir 2001, 17, 3844-3851.

95. http://www.hmi.de

96. Garidel, P.; Johann, C.; Mennicke, L.; Blume, A. The mixing behavior of pseudobinary phosphatidylcholine- phosphatidylglycerol mixtures as a function of $\mathrm{pH}$ and chain length. Eur. Biophys. J. 1997, 26, 447-459.

97. Provencher, S. W. Contin: a general purpose constrained regularisation program for inverting noisy linear algebraic and integral equation. Comput. Phys. Commun. 1982, 27, 229-242.

98. Forte, L.; Andrieux, K.; Keller, G.; Grabielle-Madelmont, C.; Lesieur, S.; Paternoster, M.; Ollivon, M.; Bourgaux, C.; Lesieur, P. Sodium taurocholate-induced lamellar-micellar phase transitions of DPPC. Determined by DSC and X-ray diffraction. J. Therm. Anal. 1998, 51, 773782.

Sample availability: Contact the authors.

(c) 2007 by MDPI (http://www.mdpi.org). Reproduction is permitted for noncommercial purposes. 